OPEN ACCESS

Edited by:

Eloi R. Verrier

INSERM UMR_S1110 Institute de Recherche sur les Maladies Virales et

Hepatiques, France

Reviewed by: Jean-Pierre Levraud, Institut Pasteur, France

Felix Ellett,

Massachusetts General Hospital and Harvard Medical School, United States

*Correspondence:

Benjamin L. King benjamin.I.king@maine.edu

Specialty section: This article was submitted to Inflammation,

a section of the journal

Frontiers in Immunology

Received: 01 December 2020 Accepted: 21 April 2021

Published: 07 May 2021

Citation:

Sullivan $C$, Soos $B-L$, Millard PJ, Kim CH and King BL (2021) Modeling Virus-Induced Inflammation in Zebrafish:

A Balance Between Infection Control and Excessive Inflammation. Front. Immunol. 12:636623. doi: 10.3389/fimmu.2021.636623

\section{Modeling Virus-Induced Inflammation in Zebrafish: A Balance Between Infection Control and Excessive Inflammation}

\author{
Con Sullivan ${ }^{1}$, Brandy-Lee Soos ${ }^{2}$, Paul J. Millard ${ }^{3}$, Carol H. Kim ${ }^{4,5}$ \\ and Benjamin L. King ${ }^{2,6^{*}}$ \\ ${ }^{1}$ College of Arts and Sciences, University of Maine at Augusta, Bangor, ME, United States, ${ }^{2}$ Department of Molecular and \\ Biomedical Sciences, University of Maine, Orono, ME, United States, ${ }^{3}$ Department of Environmental and Sustainable \\ Engineering, University at Albany, Albany, NY, United States, ${ }^{4}$ Department of Biomedical Sciences, University at Albany, \\ Albany, NY, United States, ${ }^{5}$ Department of Biological Sciences, University at Albany, Albany, NY, United States, \\ ${ }_{6}^{6}$ Graduate School of Biomedical Science and Engineering, University of Maine, Orono, ME, United States
}

The inflammatory response to viral infection in humans is a dynamic process with complex cell interactions that are governed by the immune system and influenced by both host and viral factors. Due to this complexity, the relative contributions of the virus and host factors are best studied in vivo using animal models. In this review, we describe how the zebrafish (Danio rerio) has been used as a powerful model to study host-virus interactions and inflammation by combining robust forward and reverse genetic tools with in vivo imaging of transparent embryos and larvae. The innate immune system has an essential role in the initial inflammatory response to viral infection. Focused studies of the innate immune response to viral infection are possible using the zebrafish model as there is a 4-6 week timeframe during development where they have a functional innate immune system dominated by neutrophils and macrophages. During this timeframe, zebrafish lack a functional adaptive immune system, so it is possible to study the innate immune response in isolation. Sequencing of the zebrafish genome has revealed significant genetic conservation with the human genome, and multiple studies have revealed both functional conservation of genes, including those critical to host cell infection and host cell inflammatory response. In addition to studying several fish viruses, zebrafish infection models have been developed for several human viruses, including influenza A, noroviruses, chikungunya, Zika, dengue, herpes simplex virus type 1, Sindbis, and hepatitis C virus. The development of these diverse viral infection models, coupled with the inherent strengths of the zebrafish model, particularly as it relates to our understanding of macrophage and neutrophil biology, offers opportunities for far more intensive studies aimed at understanding conserved host responses to viral infection. In this context, we review aspects relating to the evolution of innate immunity, including the evolution of viral pattern recognition receptors, interferons and interferon receptors, and non-coding RNAs.

Keywords: innate immunity, neutrophils, reactive oxidative species, inflammation, virus infection, zebrafish 


\section{INTRODUCTION}

Deadly hyperinflammatory responses to diseases like COVID-19 and influenza A result when the immune system overreacts (1-6). Cytokine storms induced by viral infections trigger this hyperinflammatory state, leading to serious consequences, including acute respiratory distress syndrome (ARDS), pulmonary edema, multiple organ failure, and death. The antiviral response encoded in vertebrate genomes incorporates an inflammatory rheostat (7) that is designed to ramp up or tamp down in response to infection. This response provides the host a measure of resilience and promotes its survivability. Under some circumstances, this inflammatory response to viral infection may become dysregulated, at which point an immunological tipping point is reached, leading to increased rates of mortality. This review describes progress in using the zebrafish (Danio rerio) as a powerful model system for the study of infection and inflammation, and it is increasingly being used to model human viral infections. Zebrafish possess several inherent characteristics that make them excellent biomedical and biological model systems, including optically clear embryos, high fecundity, a fully sequenced genome, amenability to multiple modes of injection and manipulation, and robust forward and reverse genetics tools. We review recent studies on viral recognition receptors in zebrafish that are homologous to those found on human cells. For example, we have shown that zebrafish possess $\alpha 2,3$ - and $\alpha 2-6$-linked sialic acid receptors that are required for infection by certain influenza A virus (IAV) strains, including H1N1 (8). Because human viruses can infect zebrafish cells, it is possible to recapitulate aspects of the human viral disease in zebrafish, including the host inflammatory response. Many elements of the host immune response to human viral infection are retained in zebrafish, and this is owed to significant cellular and molecular conservation between zebrafish and humans. As neutrophils have critical roles in inflammation, we begin our review on neutrophils and their roles in antiviral response pathways that include toll-like receptors (TLRs), interferon (IFN) signaling, and the respiratory burst response. Next, we review zebrafish studies on fish and human viruses and include methodological details about these zebrafish models and functional assays. We also describe recent studies of non-coding RNAs that regulate neutrophil function. It is our view that the zebrafish offers tremendous promise as a model to understand how some of the mechanisms underlying a normal immune response to viral infection in humans become excessive, leading to increasing morbidities and mortalities.

\section{IMMUNE CELL CONSERVATION IN ZEBRAFISH}

\section{Definitive Hematopoiesis}

In zebrafish, definitive hematopoiesis begins as early as 26 hours post-fertilization (hpf) and gives rise to self-renewing hematopoietic stem cells (HSCs) that can differentiate into cells with myeloid, lymphoid, and erythroid lineages (9). The sites of definitive hematopoiesis differ between zebrafish and humans. For zebrafish, definitive hematopoiesis transitions from the ventral wall of the dorsal aorta ( $26 \mathrm{hpf}$ ) through the caudal hematopoietic tissue (CHT) ( 2 days post-fertilization (dpf) ) and eventually to the thymus ( $\sim 3 \mathrm{dpf}$ ) or the pronephros/kidney ( $\sim 4 \mathrm{dpf})(9-11)$. In mammals, definitive hematopoiesis is transitory as well, moving from the aorta-gonad-mesonephros region in the ventral wall of the dorsal aorta, to the mammalian fetal liver, and finally to the bone marrow (12). The earliest stage of definitive hematopoiesis in both zebrafish and mammals is restricted to analogous ventral dorsal aorta regions. From there, the anatomical sites of hematapoiesis differ (11). Nonetheless, the genetics and molecular signaling underlying definitive hematopoiesis in vertebrates are largely conserved across species. Importantly, the morphology and function of zebrafish neutrophils are conserved with mammalian neutrophils (13). As many studies of neutrophil function in zebrafish are done during embryonic and larval stages, it is worthwhile noting that neutrophils also arise from hematopoietic precursors in the yolk sac (14). As neutrophils are the first immune cells that migrate to the site of inflammation, our review will focus on these phagocytes.

\section{Neutrophils}

The first immune cells that migrate to the site of inflammation are neutrophils (15). Zebrafish neutrophils, also known as heterophils, respond to infection and injury in a manner that is similar to human neutrophils. For example, zebrafish neutrophils have been shown to migrate to the sites of bacterial (16), fungal (17-23), and viral $(8,24,25)$ infections. Additionally, wounding studies have demonstrated neutrophil migration to the site of injury in zebrafish (26). Like human neutrophils, the response of zebrafish neutrophils to pathogens include phagocytosis, degranulation, and formation of neutrophil extracellular traps (NETs). Central to the response of neutrophils is the release of reactive oxidative species (ROS), which is described in detail later in this review. Both azurophillic and non-azurophillic granules are found in zebrafish neutrophils, with azurophillic granules being more abundant $(27,28)$. Like primary azurophilic granules in mammalian neutrophils, zebrafish neutrophil granules contain the enzyme myeloperoxidase (Mpx) (27). During respiratory burst, Mpx catalyzes the conversion of $\mathrm{H}_{2} \mathrm{O}_{2}$ and $\mathrm{Cl}^{-}$to produce cytoxic hypochlorous acid ( $\mathrm{HOCl}$ (29). Neutrophils also generate reactive nitrogen species (NO). NETs are released by neutrophils through a cell death process, named NETosis, to inactivate and destroy extracellular viral particles, bacteria, and fungi. In human neutrophils, NETs are composed of a scaffold of decondensed chromatin with at least 24 cytosolic and granule proteins, including myeloidperoxidase (MPO) and neutrophil elastase (ELANE) (30). NETs were observed to be generated by neutrophils found within whole zebrafish kidney tissue ex vivo following stimulation with calcium ionophore, phorbol myristate acetate (PMA), and $\beta$-glucan (31). Two features associated with NETs have been observed at the sites of localized hindbrain Candida albicans infection in vivo. First, increased levels of extracellular DNA were detected with neutrophil invasion following hindbrain C. albicans infection (32). Second, extrusion of a neutrophil-specific histone $2 \mathrm{~B}$-mCherry fusion protein was observed following neutrophil recruitment to C. albicans but not 
C. auris hindbrain infection (33). The activation and translocation of NETs is initiated by ROS that, in turn, stimulate MPO and ELANE expression in mammalian cells (34). Even though mammalian ELANE does not have an obvious homolog in zebrafish (35), elastase activity was associated with zebrafish NETs (31). Given the central role of ROS in the neutrophil response, a major focus in this review will be on ROS.

\section{Neutrophil and Macrophage Reporter Lines}

Several zebrafish fluorescent reporter strains have been developed to visualize neutrophils and macrophages in vivo, and for fluorescentlyactivated cell sorting (FACS). Transgenic zebrafish neutrophil reporter lines have used $m p x$ and lysozyme (lyz) promoters to drive the expression of fluorescent proteins. Frequently used neutrophil reporter lines include the GFP reporters, $\operatorname{Tg}(m p x$ : GFP $)^{i 114}$ (36), $\operatorname{Tg}(m p x: G F P)^{u w m 1}$ (37) and $\operatorname{Tg}(\text { lyz:EGFP })^{n z 117}$ (38), and the red fluorescent protein reporters, $\operatorname{Tg}(m p x: m C h e r r y)^{u w m 7}(39)$ and $\operatorname{Tg}(l y z: D s R E D 2)^{n z 50}$ (38). Additional reporter lines using the photoconvertible fluorescent reporter, Dendra2 (40), have been developed to study migration of macrophages and neutrophils. Dendra2 protein photoswitches from green to red following exposure to visible blue or UV light. This photoconvertible reporter line enables tracking of neutrophil forward and reverse migration (41). Another photoconvertible protein, Kaede, has also been used to study neutrophil migration when expressed as part of a GAL4/UAS bipartite expression system, such as the $\operatorname{Tg}(m p x: G a l 4) ; \operatorname{Tg}(U A S$ : Kaede $)^{i 222}$ line. As many zebrafish macrophage reporter lines have also been developed, it is possible to use double transgenic lines, such as Tg(mpeg1:Gal4-VP16/UAS : Kaede/mpx:EGFP), to allow for in vivo imaging of neutrophils and macrophages simultaneously (42). These macrophage reporter lines use a promoter from the membrane attack complex/perforin-domain containing gene, macrophage expressed gene 1, tandem duplicate 1 (mpeg1.1) (43), to drive the expression of reporters, such as EGFP ( $\left.\mathrm{Tg}(\mathrm{mpeg1} 1 \mathrm{e} G F P)^{g / 22}\right)(42)$, mCherry $(\mathrm{Tg}$ (mpeg1:mCherry $)^{g l 23}$ ) (42), and YFP (Tg(mpeg1:YFP $)^{w 200}$ (44). Migration of macrophages can also be monitored using the Dendra2 reporter in the $\operatorname{Tg}(m p e g 1: D e n d r a 2)^{u w m 12}$ line (45). The promoter for microfibril associated protein 4 , tandem duplicate 1 (mfap4.1) has also been used for macrophage reporter lines (46) as the expression of mpeg1 was shown to be attenuated following infection of Salmonella thyphimurium and Mycobacterium marinum (47). Several of these neutrophil and macrophage reporter lines have been used for FACS for cell-specific functional analysis $(38,48,49)$.

\section{OVERVIEW OF ANTIVIRAL RESPONSE}

Defense against viral infection is governed by both the innate and adaptive immune systems. Even though the adaptive immune system can provide protection from viral infection through $B$ and $\mathrm{T}$ lymphocytes, the innate immune system provides an initial response to viral infection and is the focus of this review. The innate immune system includes physical barriers, phagocytic cells, pattern recognition receptors (PRRs), interferons and interferon-stimulated genes (ISGs), cytokines and chemokines, and the complement system. Physical barriers include the mucus barrier that is composed of polymeric secreted mucins. Phagocytes include neutrophils and macrophages that can kill virus particles and recruit additional phagocytes to sites of infection. An important response of phagocytes is a respiratory burst response that releases ROS to kill virus particles and recruit additional phagocytes. Critical to the activation of immune response are PRRs that bind pathogen-associated molecular patterns (PAMPs) and damage-associated molecular patterns (DAMPs) and trigger the expression of interferon and cytokines through $\mathrm{NF}-\kappa \mathrm{B}$ and interferon response factor (IRF) transcription factors. Interferon elicits a potent response to viral infection that includes the activation of a battery of ISGs. Inflammatory cytokines and chemokines recruit phagocytes at the site of infection. The complement system functions to respond to microbial pathogens by recognizing motifs through three convergent activation pathways that lead to complementmediated lysis (50). Figure 1 illustrates components of response to viral infection using IAV as an example. Genes that have shown to respond to the inflammatory and antiviral response using zebrafish models of viral infection are shown in Tables 1 and 2 , respectively.

The zebrafish model system holds particular promise for understanding the innate immune response to viral infection. Zebrafish lack a fully functional adaptive immune response for the first 4-6 weeks of development (66) and rely upon their innate immune response for defense against all forms of infection. Many aspects of the innate immune system, including those listed below, are functionally conserved in zebrafish, and thus the zebrafish can effectively model how normal inflammatory responses to viral infections can lead to extensive tissue damage and mortality.

\section{Pattern Recognition Receptors (PRRs)}

PRRs bind PAMPs and DAMPs, triggering a signal transduction cascade that activates several transcription factors critical to the antiviral and pro-inflammatory immune response. Viral PAMPs include surface glycoproteins, single-stranded RNA, doublestranded RNA, and other RNA and DNA species. DAMPs produced by damaged cells can also activate the immune response. DAMPs include denatured intracellular proteins, such as high-mobility group box protein 1 (HMGB1) (67). PRRs include TLRs, nucleotide-binding oligomerization domain (NOD)-like receptors (NLRs), retinoic acid-inducible gene-I-like (RIG-I)-like receptors (RLRs), scavenger receptors, and C-type lectin receptors (CLRs).

PAMPs from viral particles that have entered the phagolysosomal degradation pathway are recognized by mammalian endosomal TLRs: TLR3, TLR7, TLR8 and TLR9. These TLRs traffic from the endoplasmic reticulum (ER) to endosomes with the chaperone, UNC93B1 (68). Doublestranded RNA, single-stranded RNA, RNA degradation products, and CpG-deoxynucleotides (CpG-DNA) are recognized by TLR3, TLR7, TLR8 (69) and TLR9, respectively. TLR3, TLR7, TLR8, and TLR9 are conserved in zebrafish as the homologs $t \operatorname{lr} 3$ (65), tlr7 (70), tlr8a (70), tlr8b (70), and $\operatorname{tr} 9$ (70, 71) (Table 3). In zebrafish, two additional antiviral TLRs, $t \operatorname{tr} 21$ and th22, have been described that recognize CpG-DNA (71) 


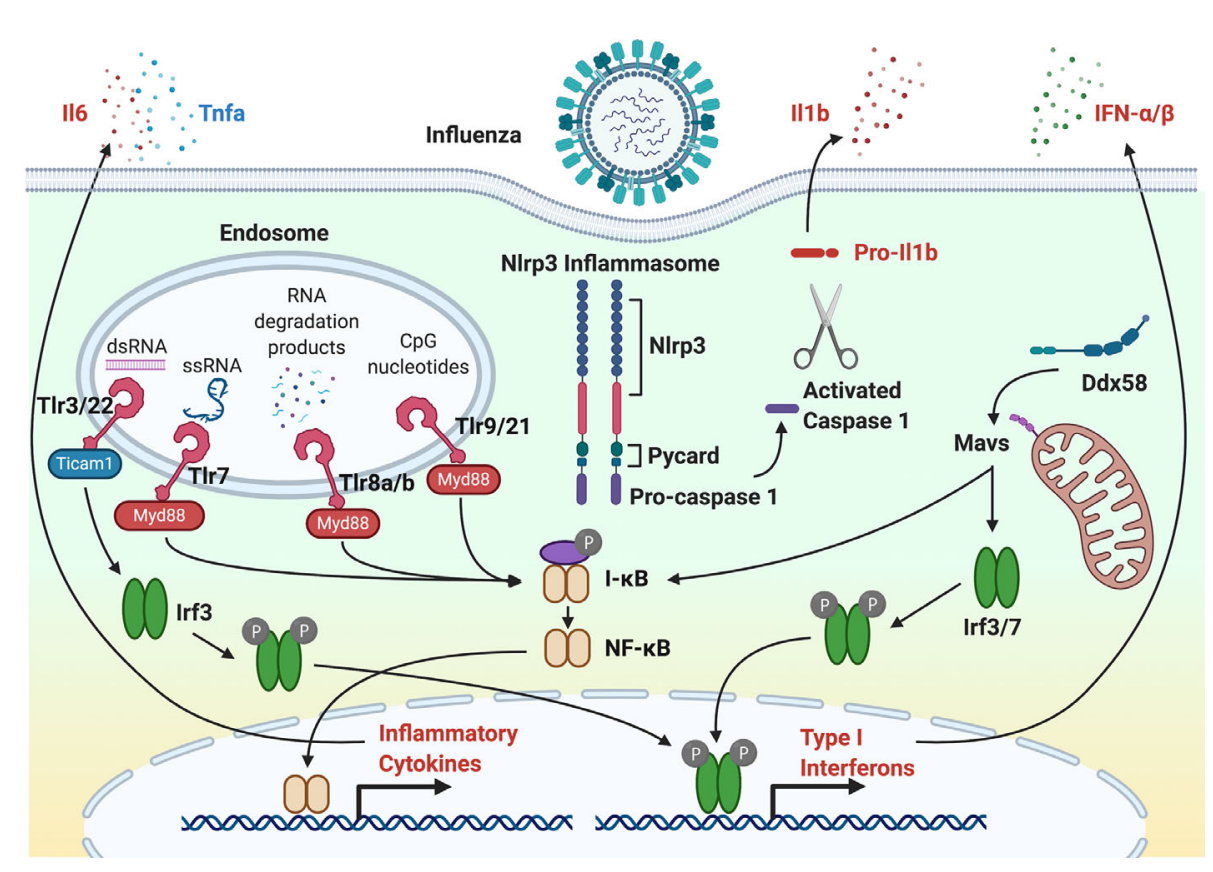

FIGURE 1 | The antiviral response to Influenza A Virus infection. Following IAV entry and infection, single-stranded RNA (ssRNA) and RNA degradation products incorporated into endosomes are recognized by TIr7 and TIr8a/b, respectively. In other virus infections, double-stranded RNA by TIr3 and TIr22. CpG motifs are recognized and TIr9 and TIr21. For TIr7, TIr8a/b and TIr9, the TLR-adaptor, Myd88, activates the NF-kB transcription factor through IkB. NF-kB initiates transcription of inflammatory cytokines, such as $\| 6$, $\| 1 \mathrm{~b}$, and Tnfa. For TIr3, the TLR-adapter, Ticam1, activates IIf3 that initiates transcription of type I interferons. DAMPs and PAMPs can activate the NIrp3 inflammasome through activated caspase 1. Activation of RIG-I (Ddx58) by cytosolic viral RNA activates Irf3 and Irf7 transcription factors through Mavs. Iff3 and Irf7 initiate the expression of type 1 interferons that further exacerbates the antiviral innate immune response to infection.

TABLE 1 | Table of proinflammatory genes studied in zebrafish models of viral infection.

\section{Gene}

Symbol
Example Viruses

Group V

\begin{tabular}{llc}
\hline Spring Viremia of Carp & Tilapia Lake & Snakehead \\
Virus & Virus & Rhabdovirus \\
(SVCV) & (TLV) & (SHRV)
\end{tabular}

Infectious Hematopoietic Necrosis Virus (IHNV)

(IAV)

\begin{tabular}{lccc}
\hline caspa & $(51)$ & & \\
cxcl8a & $(52)$ & $(53)$ & $(53)$ \\
ifng1 & $(54)$ & $(53)$ & \\
ifnphi1 & $(51,55,56) \#(57)$ & $(53)$ & \\
ifnphi2 & $(51)$ & $(53)$ \\
il1b & $(51,52,54)$ & $(53)$ \\
iif3 & $(52,56,62)$ & \\
irf7 & $(52,62)$ & \\
Ita & $(52,56)$ & \\
sting1 & $(62)$ & $(53)$ \\
pycard & $(51)$ & \\
rarres3 & $(51)$ & \\
tnfa & $(51,54,55)$ & \\
tnfb & $(55)$ &
\end{tabular}

"Functional study.

and double-stranded RNA $(73,79)$, respectively. Homologs of tlr21 and tlr22 have not been observed in mammalian genomes, but $t$ tr21 is conserved in avian species.

The TLR signaling pathway in zebrafish includes the adaptor proteins Myd88, Tirap, Ticam1, and Sarm1 for downstream signaling. The gene encoding the Ticam2 adaptor protein found in mammals is absent in zebrafish (74). In mammals, Myd88 is required for all TLRs except for TLR3 and TLR4 (80). TLR signaling is mediated by tumor necrosis factor receptor associated factor 6 (TRAF6) and interleukin-1 
TABLE 2 | Table of antiviral genes studied in zebrafish models of viral infection.

\begin{tabular}{|c|c|c|c|c|c|c|}
\hline \multirow{3}{*}{$\begin{array}{l}\text { Gene } \\
\text { Symbol }\end{array}$} & \multicolumn{6}{|c|}{ Example Viruses } \\
\hline & \multirow{2}{*}{$\begin{array}{c}\text { Group III } \\
\text { Infectious Pancreatic } \\
\text { Necrosis Virus }\end{array}$} & \multicolumn{5}{|c|}{ Group V } \\
\hline & & $\begin{array}{l}\text { Spring Viremia of } \\
\text { Carp Virus }\end{array}$ & $\begin{array}{l}\text { Tilapia Lake } \\
\text { Virus }\end{array}$ & $\begin{array}{l}\text { Snakehead } \\
\text { Rhabdovirus }\end{array}$ & $\begin{array}{l}\text { Infectious Hematopoietic } \\
\text { Necrosis Virus }\end{array}$ & $\begin{array}{c}\text { Influenza A } \\
\text { Virus }\end{array}$ \\
\hline defb2 & & (54) & & & & \\
\hline foxo3b & & (52) & & & & \\
\hline ifit8 & & (51) & & & & \\
\hline ifit14 & & (51) & & & & \\
\hline isg15 & (61) & (61) & & & (61) & \\
\hline mavs & & $(62,63)$ & & & & \\
\hline ifih1 & & (63) & & (60) & & \\
\hline$m x a$ & & $(51,54,63)$ & (53) & (59) & & (8) \\
\hline$m \times b$ & & $(51,54,55)$ & & & & \\
\hline$m \times c$ & & $(52,54,56)$ & & & & \\
\hline nod2 & & (63) & & & & \\
\hline$p k z$ & & (56) & & & & \\
\hline prmt3 & & (56) & & & & \\
\hline rela & & (64) & & & & \\
\hline$d d \times 58$ & & $(51,52,62,63)$ & (53) & & & \\
\hline ripk2 & & (63) & & & & \\
\hline tbk1 & & (62) & & & & \\
\hline t/r3 & & (51) & (53) & (65) & & \\
\hline $\operatorname{tr} 7$ & & $(51)$ & & & & \\
\hline tIr8a & & (51) & & & & \\
\hline t/r22 & & (51) & (53) & & & \\
\hline rsad2 & & (55) & & & & \\
\hline
\end{tabular}

receptor-associated kinase 4 (IRAK4) that activate the NFKB, IRF, STAT, ATF, and AP-1 families of transcription factors. The expression of tlr3, traf6 and irak4 was upregulated in embryonic and adult zebrafish following snakehead rhabdovirus (SHRV) infection (65). Beyond these four TLRs, knockdown of two adaptors for TLR signaling, Ly86 and Cd180, found increased susceptibility to spring viremia carp virus (SVCV) in zebrafish larvae (81). In mammals, LY86 and CD180 are adaptors for TLR4, a TLR that responds to lipopolysaccharide (LPS).

We previously described a model for the history of TLR4 genes in humans and zebrafish that we believe accounts for the functional divergence that has been observed, specifically in regards to the reduced LPS sensitivity seen in fishes (75). We hypothesize that TLR4 was duplicated in an ancestral genome with the second whole genome duplication event, yielding the TLR $4 A$ and TLR $4 B$ genes (75). Our model projects that there was lineage divergence and a reciprocal loss of TLR 4 ohnologs. The ancestral TLR $4 A$ was retained in the lineage that gave rise to mammals, including humans, and $T L R 4 B$ was lost. The TLR $4 A$ gene, by convention, is referred to as $T L R 4$. In the lineage that gave rise to zebrafish, the ancestral TLR $4 B$ gene was retained, and the ancestral TLR4A gene was lost. The ancestral TLR $4 B$ gene was subsequently duplicated, giving rise to the tlr $4 b a$ and $t l r 4 b b$ paralogs observed in the current zebrafish genome.

There are data that indicate that TLR3, TLR7, TLR8, and TLR9 are, at least to some extent, functionally conserved in zebrafish as the homologs $t \operatorname{lr} 3, \operatorname{tl} 7, \operatorname{tr} 8 a, t \operatorname{lr} 8 b$, and $t \operatorname{lr} 9$. To fully exploit the zebrafish model as a means to understand antiviral responses, it is necessary to undertake meticulous gene history studies to support orthology. Indeed, based on data available through Ensembl (82), ZFIN (83), and the Synteny Database
(84), there appear in certain instances to be discrepancies in the identification and/or naming of zebrafish TLR genes that consequently imply a gene orthology (or lack of orthology) and functional conservation with human TLR genes despite sufficient evidence. For example, ZFIN predicts that zebrafish $t \operatorname{tr} 8 a$ and $t l r 8 b$ are co-orthologous to human TLR8; however, this prediction is not supported by Ensembl or the Synteny Database where they do not list any orthologs for human TLR8. According to Ensembl, zebrafish trr8b has a one-to-many orthologous relationship to the spotted gar gene ENSLOCG00000013826, which has been annotated as tlr3. Due to its evolutionary position as a non-teleost and non-tetrapod, jawed vertebrate model organism, the spotted gar genome serves as an "orthology bridge" to link the gene histories of the zebrafish (and other teleosts) and human genomes (85). The ENSLOCG00000013826 gene has no human ortholog but does have a one-to-many orthologous relationship to a zebrafish gene annotated as tlr3. According to Ensembl and the Synteny Database, this zebrafish tlr3 gene is an ortholog to human TLR3. This brief example demonstrates the inconsistencies present in current zebrafish databases and lends credence to the idea that the tlr8 paralogs found in zebrafish (and other fishes) have no ortholog in the human genome, and thus are likely misnamed. In addition to these issues related to the evolutionary history of zebrafish $\mathrm{tl}$ genes, there are also important concerns about the mechanisms by which the proteins encoded by these genes are engaged. Specifically, there is evidence that zebrafish TLR proteins do not bind PAMPs and other ligands in the same manner as human TLR proteins (69). There is also evidence indicating that the mechanisms by which zebrafish TLR proteins engage TIR 
TABLE 3 | TLR genes in zebrafish.

\begin{tabular}{|c|c|c|c|c|c|c|c|}
\hline $\begin{array}{l}\text { Zebrafish Gene } \\
\text { Symbol }\end{array}$ & $\begin{array}{c}\text { Ensembl Zebrafish } \\
\text { Gene ID }\end{array}$ & $\begin{array}{c}\text { Zebrafish } \\
\text { Chr. }\end{array}$ & $\begin{array}{l}\text { Zebrafish } \\
\text { Refs. }\end{array}$ & $\begin{array}{l}\text { Predicted Human } \\
\text { Ortholog }\end{array}$ & $\begin{array}{l}\text { Ensembl Human } \\
\text { Ortholog Gene ID }\end{array}$ & $\begin{array}{l}\text { Human } \\
\text { Chr. }\end{array}$ & Orthology Resource(s) \\
\hline \multirow[t]{2}{*}{ tIr1 } & \multirow[t]{2}{*}{ ENSDARG00000100649 } & \multirow[t]{2}{*}{14} & \multirow[t]{2}{*}{$(70)$} & $T L R 1^{*}$ & ENSG00000174125 & 4 & \multirow{2}{*}{$\begin{array}{l}\text { Synteny DB, ZFIN } \\
\text { Ensembl }\end{array}$} \\
\hline & & & & $T L R 6^{*}$ & ENSG00000174130 & 4 & \\
\hline trr2 & ENSDARG00000037758 & 1 & $(70,72)$ & TLR2 & ENSG00000137462 & 4 & $\begin{array}{l}\text { Synteny DB, ZFIN, } \\
\text { Ensembl }\end{array}$ \\
\hline t/r3 & ENSDARG00000016065 & 1 & $(65,73,74)$ & TLR3 & ENSG00000164342 & 4 & Synteny DB, ZFIN \\
\hline t/r4al & ENSDARG00000075671 & 13 & & $\star \star$ & & & \\
\hline tIr4ba & ENSDARG00000019742 & 13 & (75) & $\star \star$ & & & \\
\hline$t / r 4 b b$ & ENSDARG00000022048 & 13 & (75) & ** & & & \\
\hline tir5a & ENSDARG00000044415 & 20 & $(72,76)$ & TLR5 & ENSG00000187554 & 1 & Synteny DB, ZFIN \\
\hline t/r5b & ENSDARG00000052322 & 20 & $(72,76,77)$ & TLR5 & ENSG00000187554 & 1 & Synteny DB, ZFIN \\
\hline $\operatorname{ttr} 7$ & ENSDARG00000068812 & 9 & $(70,78)$ & $T L R 7$ & ENSG00000196664 & $x$ & Synteny DB, ZFIN \\
\hline trr8a & ENSDARG00000090119 & KN150362.1 & (70) & $T L R 7$ & ENSG00000196664 & $x$ & Synteny DB \\
\hline $\begin{array}{l}\text { CU914164.1 } \\
\text { (t/r8) }\end{array}$ & ENSDARG00000104832 & 9 & & TLR8 & ENSG00000101916 & $x$ & ZFIN \\
\hline \multirow[t]{2}{*}{ t/r8b } & \multirow[t]{2}{*}{ ENSDARG00000073675 } & \multirow[t]{2}{*}{10} & \multirow[t]{2}{*}{$(70)$} & $T L R 7$ & ENSG00000196664 & $x$ & \multirow{5}{*}{$\begin{array}{l}\text { Synteny DB } \\
\text { ZFIN } \\
\text { Synteny DB, } \\
\text { ZFIN }\end{array}$} \\
\hline & & & & TLR8 & ENSG00000101916 & $x$ & \\
\hline tlr9 & ENSDARG00000044490 & 8 & (71) & TLR9 & ENSG00000239732 & 3 & \\
\hline \multirow[t]{2}{*}{$\operatorname{tr} 18$} & \multirow[t]{2}{*}{ ENSDARG00000040249 } & \multirow[t]{2}{*}{16} & & \multirow[t]{2}{*}{-} & & - & \\
\hline & & & & & & - & \\
\hline $\operatorname{tir} 19$ & ENSDARG00000026663 & 16 & & - & & - & \\
\hline $\operatorname{tr} 20.1$ & ENSDARG00000115923 & 9 & & - & & - & \\
\hline $\operatorname{tr} 20.2$ & ENSDARG00000088701 & 9 & & - & & - & \\
\hline $\operatorname{tr} 20.3$ & ENSDARG00000114057 & 9 & & - & & - & \\
\hline $\operatorname{tr} 21$ & ENSDARG00000058045 & 16 & $(71)$ & - & & - & \\
\hline t/r22 & ENSDARG00000104045 & 21 & $(73,79)$ & - & & - & \\
\hline
\end{tabular}

Predictions were made using information from Ensembl, ZFIN and SyntenyDB. Ensembl gene IDs for each gene are listed, along with their respective chromosome locations.

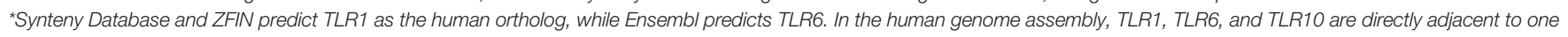
another. ${ }^{*}$ Human TLR4 is not orthologous to truba, trubb, or tIr4al (75).

Known zebrafish toll-like receptors with predicted human orthologs.

domain containing adaptor proteins may sometimes differ (74). There are also many questions related to where within or on a cell a zebrafish TLR protein is expressed. Taken together, it is clear that assumptions about zebrafish TLR protein function based upon protein similarity and even phylogenetic analyses need further verification through comprehensive gene history analysis and thorough validation through functional assays.

Cytosolic PAMPs and DAMPs are recognized by NLRs and RLRs. After ligand binding, two NLRs, NOD1 and NOD2, can activate NFKB after recruiting the serine/threonine kinase RIPK2 through MAP kinase signaling. Several NLRs, including NLRC4, NARP1 and NARP3, function as PAMP and DAMP receptors for inflammasomes. Inflammasomes are multiprotein complexes that activate inflammatory caspases and pro-inflammatory cytokines through canonical signaling and non-canonical pathways to induce pyroptosis (86). In the canonical NLRP3 inflammasome signaling pathway, ligand binding to NRLs activate caspase 1 (CASP1) that then then activates the proinflammatory cytokines, interleukin $1 \beta$ (IL1B) and interleukin 18 (IL18). Activation of CASP1 is dependent on the adaptor protein, apoptosis-associated speck-like protein containing a caspase-recruitment domain (PYCARD), which is also part of the inflammasome complex. In the non-canonical NLRP3 inflammasome signaling pathway, activated inflammasomes hydrolyze gasdermin D (GSDMD) leading to a N-terminal fragment that perforates the cell membrane to enable the release cytokines and subsequent cell death through pyroptosis.
Inflammasome NLRs recognize ligands from both infection and sterile stressors. NLRP3 recognizes double-stranded RNA and activates CASP1 after binding the adaptor protein, apoptosisassociated speck-like protein containing a caspase-recruitment domain (PYCARD). Pycard-dependent activation of Illb by Nlrp3 inflammasomes through caspase 1 (caspa) was found to be conserved in zebrafish larvae using morpholino knockdown of Nlrp3 and a nlrp3 mutant challenged with Edwardsiella tarda (87). Li et al. also showed Nlrp3 initiated cell pyroptosis through Caspb activation in a gasdermin E (Gsdmeb/Gsdmea)-dependent, but independent of Pycard-activation (87). While several aspects of inflammasome signaling are conserved in zebrafish, differences do exist. Zebrafish have over 400 NLR genes (88), but only two have been associated with inflammasome function, nlrp1 (89), and nlrp3 $(87,90)$, that were shown to function similar to NLRP1. An additional inflammasome adaptor, caiap, was found to regulate inflammasome activation in zebrafish in response to Salmonella typhimurium infection (91). While the proinflammatory cytokine, $i l 1 b$ is conserved with zebrafish, an ortholog to IL18 has not been identified in zebrafish. Homologs to IL18 have been identified in other ray-finned fishes, including the pufferfish (Takifugu rubripes) (92) and rainbow trout (Oncorhynchus mykiss) (93).

Cytosolic viral RNA can also be detected by RLRs that are a family of DExD/H box RNA helicases consisting of RIG-I (encoded by the gene DDX58), melanoma differentiationassociated factor 5 (MDA5; encoded by the gene IFIH1), and 
laboratory of genetics and physiology 2 (LGP2; encoded by the gene DHX58). Activation of RLRs by binding viral RNA leads to activation of the antiviral response and type 1 interferon (IFN) expression through interferon regulatory factor 3 (IRF3), IRF7, and NF- $\kappa \mathrm{B}$ transcription factors. Upon binding viral RNA, the CARD domains of RIG-1 and MDA5 interact with the adaptor protein, mitochondrial antiviral signaling (MAVS). The conserved role of Mavs in regulating the IFN antiviral response in zebrafish larvae has been demonstrated through studies of chikungunya virus (CHIKV) infection (94). The IFN response and survival was significantly reduced in Mavs morphants infected with CHIKV. Zebrafish homologs of DDX58, IFIH1 and DHX58 have been identified as $d d x 58$, ifih1, and $d h x 58$.

Additional PAMP receptors include scavenger receptors and CLRs. In mammalian models, the scavenger receptor, macrophage receptor with collagenous structure (MARCO), has been shown to recognize several viruses, including respiratory syncytial virus and vaccinia virus. In zebrafish, marco has been used as a marker of macrophages and dendritic cells in adults. Marco was demonstrated to be required for phagocytosis and the proinflammatory response to Mycobacterium marinum and Salmonella typhimurium in larvae (95). Increased bacterial burden and decreased proinflammatory signaling was observed in infected Marco morphants. Another scavenger receptor, the expression of cluster differentiation antigen 36 ( $c d 36)$ was upregulated in zebrafish following infection by viral hemorrhagic septicemia virus (VHSV) (96). Knockdown of $\mathrm{Cd} 36$ in zebrafish embryos resulted in higher bacterial burden following infection by Mycobacterium marinum (97). Several transmembrane CLR proteins function as PRRs on myeloid cells. Two CLRs include mannose-binding lectin 2 (MBL2) and CD209. MBL2 can activate the lectin complement pathway (98) after binding to mannose, fucose and $\mathrm{N}$ acetylglucosamine on microbial pathogens, including viruses. MBL2 was shown to bind to influenza A virus (IAV) and inhibit the hemagglutinating activity of IAV (99). CD209 can also recognize microbial pathogens, including viruses that express mannose-rich oligosaccharides. CD209 was shown to function as an attachment receptor for influenza A virus on mammalian cells and mediate sialic-acid independent attachment and infection (100). While the functions of these specific CLRs have not yet been investigated in the context of viral infection in zebrafish, both $\mathrm{mbl2}$ and $c d 209$ are present in the zebrafish genome.

The complement system has important roles in innate immunity and neutralization of viruses. Mechanisms for complement activation include C-reactive protein (CRP), and recognition of PAMPs and DAMPs. The classical, lectin and alternative complement pathways activate C3 convertase that cleaves complement component $\mathrm{C} 3$ to produce the $\mathrm{C} 3 \mathrm{a}$ and $\mathrm{C} 3 \mathrm{~b}$ peptides. In the alternative pathway, C5 convertase cleaves $\mathrm{C} 5$ to produce $\mathrm{C} 5 \mathrm{a}$ and $\mathrm{C} 5 \mathrm{~b}$. Both anaphylatoxin, $\mathrm{C} 3 \mathrm{a}$, and $\mathrm{C} 5 \mathrm{a}$ have important roles in regulating inflammation (101). C3a inhibits the migration of neutrophils to sites of acute inflammation (102) whereas C5a has the opposite function (103). The complement system is largely conserved in zebrafish, but there are differences (50).
For example, there are two groups of paralogs for C3, c3a with six paralogs (c3a.1, c3a.2, c3a.3, c3a.4, c3a.5, and $c 3 a .6)$, and $c 3 b$ with two paralogs ( $c 3 b .1$ and $c 3 b .2)$, however there is only one C5 homolog, c5. A zebrafish study of CRP genes and proteins in the response to SVCV and VHSV infection showed that crp2/Crp2 and crp5/Crp5 had the largest increases in expression (104).

\section{Interferons and Interferon-Responsive Genes}

The innate immune response to viral infection is governed by interferon (IFN) and genes induced by interferon. In mammals, there are three classes of interferon genes (IFNs): type I ( $\alpha, \beta, \omega, \varepsilon$, and $\kappa)$, type II $(\gamma)$ and type III $(\lambda)$. Both type I and type III IFNs have well established antiviral activities in mammals, whereas the function of type II IFNs is associated with the response to bacterial infection. Type II IFNs do not exclusively respond to bacterial infection, as they have been associated with the response to vesicular stomatitis virus infection in mice (105). Beyond the type I IFN genes discussed in detail below, zebrafish have two paralogs of the type II IFN, IFNG, named ifng1 (interferon gamma 1) and ifnglr (interferon gamma 1 related) (106).

Activation of IFN is a conserved response to viral infection across vertebrates, including zebrafish. One of the first studies in zebrafish showed that IFN expression was induced in zebrafish liver cells when infected by SHRV (58). In addition to the IFN gene first characterized in that study (now named ifnph1), zebrafish have three additional IFN genes (ifnphi2, ifnphi3, ifnphi4) that are activated in response to viral infection (Table 4) (107, 108). Considerable efforts to identify and characterize IFN genes in fishes have been undertaken, and several excellent reviews describing the complexity of IFN signaling in fishes, including zebrafish, have recently been published (110-112). Type I IFN signaling mediated by zebrafish bears many similarities but also significantly differs from that observed in humans. For example, at the gene level, fish type I IFN (including zebrafish) have retained introns, while mammalian type I IFNs do not. It is thought that the absence of mammalian type I IFNs was a result of a retrotransposition event in amniotes (111). In addition, unlike mammalian type I IFNs, which are typically secreted upon viral induction, fish type I IFNs can be alternatively transcribed with or without signal peptides for extracellular expression (57). Zebrafish type I IFNs can be separated into two groups: Group I and Group II (111). Group I IFNs include Ifnphi1 and Ifnphi4, while group II IFNs include Ifnphi2 and Ifnphi3. Group I IFNs are characterized by a pair of conserved cysteine residues that form a disulfide bridge. Group II IFNs are characterized by two pairs of conserved cysteine residues that form two disulfide bridges (113). Group I and group II IFNs engage different receptor complexes, but each receptor complex is thought to include cytokine receptor family member b 5 (Crfb5) (108). Group I IFNs are thought to interact with $\mathrm{Crfb} 1 / \mathrm{Crfb} 5$ complexes, and group II IFNs are thought to interact with $\mathrm{Crfb} 2 / \mathrm{Crfb} 5$ complexes. Interestingly, knockdown of caveolin 1 (Cav1) in zebrafish disrupted Crfb1 IFN receptor clusters, thereby decreasing antiviral immune responses (114). Activation of the IFN receptor clusters signal through the Jak/ STAT pathway to activate IFN-stimulated genes (ISGs) that 
TABLE 4 | IFN genes in zebrafish.

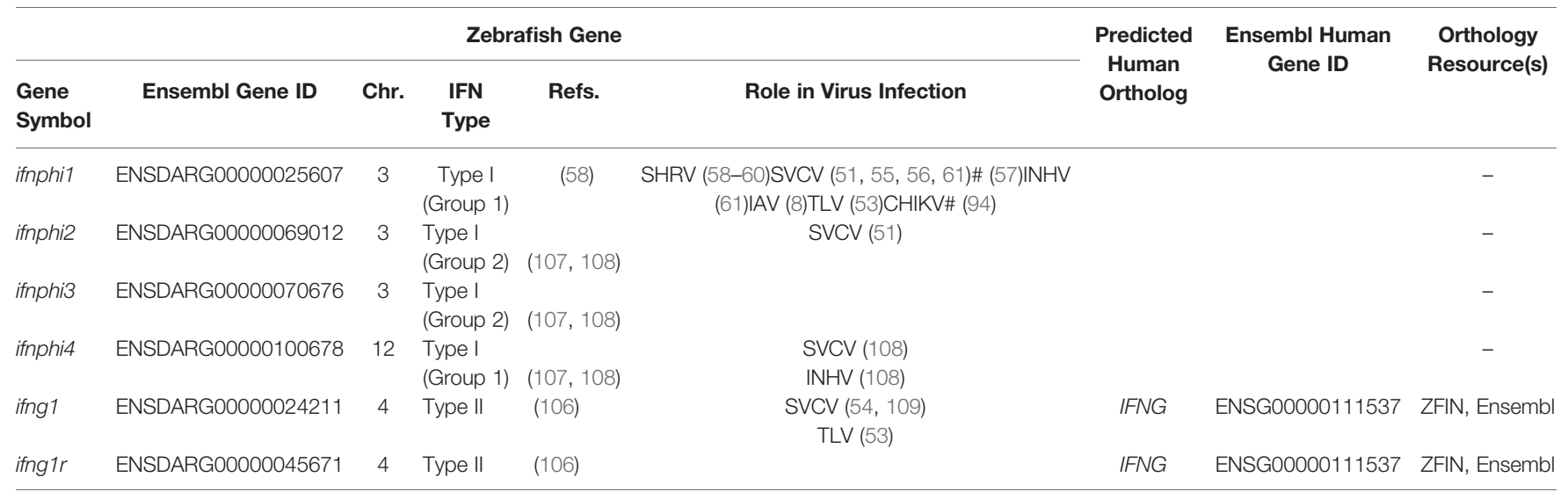

${ }^{\#}$ Functional study.

share a IFN-stimulated response element (ISRE) (115). Multiple studies have shown a large set of ISGs in response to viral infection in zebrafish, many of which have mammalian orthologs that are ISGs in mammalian models. Among some of these conserved ISGs are mxa (116), rsad2 (57), and isg15 (61). One study compared ISGs that responded to a poor IFN inducer, infectious hematopoietic necrosis virus (IHNV), to a strong IFN inducer, CHIKV, with and without knockdown of the IFN receptors, Crfb1 and Crfb2 (117). A study of zebrafish infected with SVCV found that 382 and 926 genes were differentially expressed in brain and spleen, respectively (118). Given that ISGs have antiviral effects and, in some cases, also enhance the replication of viruses (115), more studies are needed to understand the complexity of IFN signaling.

In zebrafish, the ifnphil gene can express two transcript isoforms: a longer, constitutively-expressed transcript, which lacks sequence encoding a secretion signal peptide, and thus is likely retained within the cells, and a shorter, virally-induced transcript, which contains a signal peptide that causes the protein to be secreted (57). Transcripts encoded by the ifnphil gene also exhibit discrete spatiotemporal patterns (108). Basal levels of ifnphil are elevated in adult spleens relative to whole larvae. In both adult and larval fish, viral infection could induce increased expression levels. Using the transgenic zebrafish line $\mathrm{Tg}$ (ifnphi1: $m$ Cherry), Palha et al. (94) showed expression of mCherry fluorescent protein driven by the ifnphil promoter in hepatocytes and neutrophils following infection with CHIKV. Transcripts encoded by the ifnphi2 gene were below the level of detection in larval zebrafish and were expressed levels comparable to ifnphi1 in adult spleens (108). In adult fish, splenic expression of ifnphi2 transcripts could be induced by SVCV infection. Transcripts encoded by the ifnphi3 gene are expressed at elevated basal levels in both adult spleens and whole larvae and were not induced by SVCV or IHNV infection (108). Interestingly, expression of ifnphi3 transcripts were not observed in the same cells in a ifnphi3 promoter reporter transgenic fish, although these data were shared as part of a personal communication and were not yet published (111). Transcripts encoded by the ifnphi4 gene are expressed at modest basal levels and are mildly induced by SVCV in larvae (108).

\section{RESPIRATORY BURST RESPONSE}

One of the important functions of macrophages and neutrophils during infection and injury is a respiratory (also called oxidative) burst response that functions to recruit additional phagocytes and degrade pathogens. Following a respiratory burst response, reactive oxidative species (ROS), hydrogen peroxide $\left(\mathrm{H}_{2} \mathrm{O}_{2}\right)$, and superoxide anion $\mathrm{O}_{2}^{-}$are produced by the phagocyte nicotinamide adenine dinucleotide phosphate (NADPH) oxidase (PHOX) complex (Figure 2). The PHOX complex is conserved between humans and zebrafish (119). The major catalytic component of PHOX, NOX2, is composed of $\mathrm{p} 91^{\text {phox }}$ (encoded by $c y b b$ ) and $\mathrm{p} 22^{\text {phox }}$ (encoded by cyba) and is bound to the phagosome membrane. The activity of NOX2 is stabilized and activated by three regulatory subunits, p4 $7^{\text {phox }}$ (encoded by $n c f 1$ ), p6 $7^{\text {phox }}$ (encoded by $n c f 2$ ) and p $40^{\text {phox }}$ (encoded by ncf4), along with the small GTPase, Rac (encoded by rac1). GTP-Rac interacts with NOX2 that, in turn, interacts with $\mathrm{p} 67^{\text {phox }}$ to activate NOX2 at the phagosome membrane. P4 $7^{\text {phox }}$ has major roles in both NOX2 activation and stabilization at the plasma membrane. First, phosphorylation of p $47^{\text {phox }}$ exposes two SRC-homology 3 domains that interact with the proline-rich motif of the NOX2 subunit, $\mathrm{p} 22^{\text {phox }}$. Second, additional PHOX homology domains on activated $\mathrm{p} 47^{\text {phox }}$ can bind the phosphoinositide, phosphatidylinositol 3,4-bisphosphate $(\mathrm{PI}(3,4) \mathrm{P} 2)$, that is produced by phosphoinositide-3-OH kinase (PI (3)K). Activated PHOX produces superoxide through the reduction of oxygen into superoxide.

Humans with mutations in PHOX subunits may develop chronic granulomatous disease (CGD), which is characterized by inflammatory disorders, granuloma formation, and increased susceptibility to infection. Individuals with mutations $\mathrm{p} 91^{\text {phox }}$ $(C Y B B), \mathrm{p} 22^{\text {phox }}(C Y B A), \mathrm{p} 47^{\text {phox }}(N C F 1), \mathrm{p}^{7^{\text {phox }}}(N C F 2)$, or $\mathrm{p} 40^{\text {phox }}$ (NCF4) develop CGD. Zebrafish have been used to model CGD in the context of fungal infection by Aspergillus 


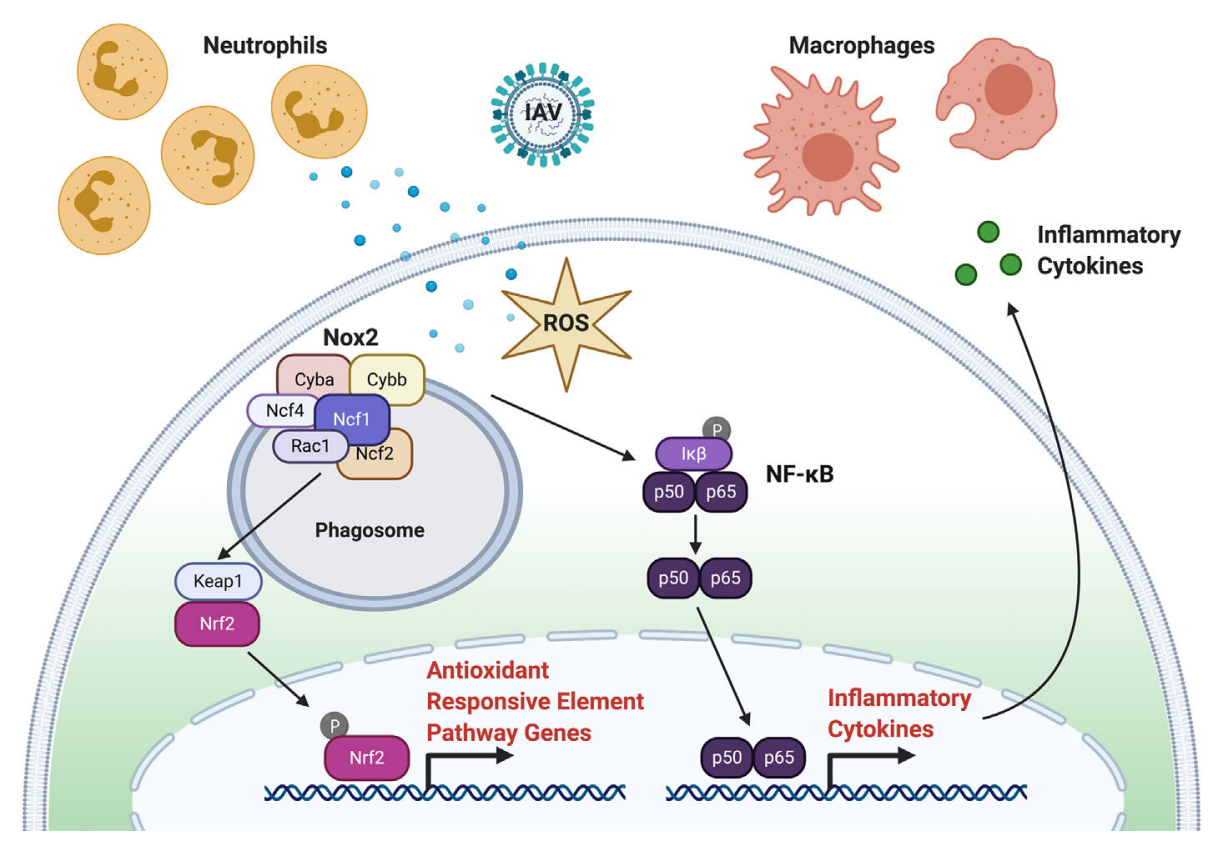

FIGURE 2 | ROS Signaling in Response to Virus Infection. Following infection, production of ROS through the respiratory burst response function to recruit phagocytes (neutrophils and macrophages) to the site of infection and inactivate virus particles. Activation of the phagocyte nicotinamide adenine dinucleotide phosphate (NADPH) oxidase (PHOX) complex produces ROS. The PHOX complex is composed to Cyba, Cybb, Ncf1, Ncf2, Ncf4, and Rac1. Activated Nox2 can activate NFKB (p60, p65) that leads to subsequent inflammatory chemokine and cytokine expression. Activated Nox2 can also activate the NRF2 transcription factor through KEAP1 to initiate the expression of antioxidants.

nidulans (120). Zebrafish embryos with a mutation in $22^{\text {phox }}$ $\left(c y b a^{s a 11798}\right)$ were observed to have decreased survival to $A$. nidulans infection, similar to what has been observed in CGD patients with fungal infections. Neutrophil migration was disrupted in the homozygous mutants as recruitment that should have peaked at $24 \mathrm{~h}$ post-infection (hpi) continued to 96 hpi. Antisense morpholino knockdown of Ncf1 in zebrafish was shown to increase susceptibility to Candida albicans infection and decrease the respiratory burst response to infection $(17,18)$. In other studies PHOX has been inhibited using small molecules, such as diphenyleneiodonium (DPI) (121), VAS-2870, and Phox-I2 (122). DPI was shown to inhibit NOX and the production of superoxide generated by PMA (phorbol 12-myristate 13-acetate)-stimulated macrophages (121). VAS-2870 was first described to inhibit platelet growth factor (PDGF)-dependent NADPH ROS production in vascular smooth muscle cells (123), but has also been shown to inhibit NADPH oxidase activity in regulatory $\mathrm{T}$ cells to block the suppression of CD4+ cells (124). Phox-I2 was designed to target the Rac1 GTPase binding site on $\mathrm{p} 67^{\text {phox }}$, and was shown to suppress ROS production in mouse neutrophils (122).

The NADPH oxidase (Nox) gene family in zebrafish is comprised of nox $1, c y b b$, nox4, nox 5 , and the dual oxidases, duox and duox2 (119). While Noxl and Cybb are part of PHOX and regulated by cytosolic factors, Nox5, Duox and Duox 2 are activated by calcium $\left(\mathrm{Ca}^{2+}\right)$ as they share helix-loop-helix EFhand domains. Like Cybb, Nox4 is stabilized by $\mathrm{p} 22^{\text {phox }}$, but it is constitutively active. Nox family members also differ by their expression and roles in different tissues. For example, human NOX1, NOX3, NOX4, NOX5, and DUOX2 are expressed in cardiovascular tissues. During the first 2 days of zebrafish embryonic development, the expression of $c y b b$ was stable during the first 2 days of development with nox 1 , nox 5 and duox being more dynamic (125). Zebrafish Duox was shown to be required for the recruitment of neutrophils to fin bud injury by generating a $\mathrm{H}_{2} \mathrm{O}_{2}$ gradient (26). Duox was also shown to be required for peripheral axon regeneration in zebrafish (126). Several NAPDH oxidase inhibitors have been developed in addition to DPI and VAS-2870, including the general NADPH inhibitor celastrol. Celastrol was shown to have higher inhibitory activity for Nox1 and Nox 2 than Nox4 and Nox5 in zebrafish embryos (127). Nox1 inhibitors of human NOX1 include ML171 (128). GKT137831 and GKT136901 were shown to be an inhibitors of mouse NOX1 and NOX4 (129, 130). Specific NOX4 inhibitors include GLX7013114 (131), GKT137928 (132) and ACD084 (133). These and other small molecule inhibitors may be useful to screen for the relative contribution of different NADPH oxidases to inflammatory responses during viral infection.

The amount of ROS production following a respiratory burst response is indicative of the intensity of the immune response and overall health of the organism. A method to assay the respiratory burst response was developed for zebrafish embryos and adult tissues (134-136). This assay measures production of $\mathrm{H}_{2} \mathrm{O}_{2}$ in response to phorbol myristate acetate (PMA) by detecting the oxidation of dihydrodichlorofluorescein $\left(\mathrm{H}_{2} \mathrm{DCF}\right)$ 
to the fluorescent product, dichlorofluorescein (DCF) to determine the fold induction of the respiratory burst (16). These assays have been used to study how low-dose arsenic reduces the capacity of zebrafish embryos infected with SHRV to mount a respiratory burst response (137). The same assays have been used to measure the respiratory burst response in zebrafish embryos following bacterial $(16,137)$ and fungal infection (18). A single cell respiratory burst assay has been developed to complement "whole embryo" methods described above (138). Dissociated cells from zebrafish embryos are stimulated with an oxidant, such as rotenone or $\mathrm{H}_{2} \mathrm{O}_{2}$, incubated with a fluorescent ROS-detecting probe, such as CellROX, and then analyzed using FACS. ROS from specific cell types can be measured by assaying fluorescent reporter lines, such as neutrophils from the $\operatorname{Tg}(m p x$ : $E G F P)$ line, to measure respiratory burst activity specifically in zebrafish neutrophils. This method has recently been used to study the roles of neutrophils in excessive inflammation following tissue injury in cystic fibrosis transmembrane conductance regulator (cftr) zebrafish mutants (139).

Apoptosis of neutrophils at the site of inflammation is one mechanism by which inflammation is resolved. A method to measure neutrophil apoptosis at the site of tailfin injury was developed for $\operatorname{Tg}(m p x: G F P)^{i 114}$ zebrafish embryos using immunohistochemistry to screen for pharmacological agents that could promote neutrophil apoptosis (140). Pyocyanin a phenazine pigment produced by Pseudomonas aeruginosa, and roscovitine, an inhibitor of cyclin-dependent kinases, both reduced the number of neutrophils at the site of injury at 24 hours post injury. Agents to delay neutrophil apoptosis and prolong inflammation were also screened. Of the agents tested, the dipeptide pan-caspase inhibitor, benzyloxycarbonyl-Val-Aspfluoromethylketone (zVD.fmk), decreased neutrophil apoptosis the most. This inhibitor was previously shown to prolong inflammation following tailfin injury in zebrafish embyros (36).

The distribution of ROS in zebrafish embryos has been assayed using high resolution intravital imaging. ROS can be detected using fluorescent imaging of zebrafish embryos treated with the cell-permeable dye, dihydroethdium (DHE), that is sensitive to superoxide $(141,142)$. DHE has blue fluorescence until it is oxidized by superoxide to form oxyethidium that emits red fluorescence and intercalates with nucleic acids (143). Phan et al. developed a model of bacterial infection that stimulated neutrophil and macrophage activation by injecting Escherichia coli into the notocord that was impenetrable by phagocytes (144). The role of neutrophil generated superoxide to clear infection was characterized using this model. Using the DHE assay, superoxide production was observed in neutrophils of infected $\operatorname{Tg}(m p x: G F P)$ embryos compared to controls. The superoxide response was shown to be neutrophil specific by examining infected embryos treated with Lipo-Clodronate to deplete macrophages, and colony stimulating factor 3 receptor (Csf3r) morphants that had depleted neutrophils.

Intracellular hydrogen peroxide $\left(\mathrm{H}_{2} \mathrm{O}_{2}\right)$ production has been visualized in zebrafish using the fluorescent reporter protein, $\mathrm{HyPer}(26,145) . \mathrm{H}_{2} \mathrm{O}_{2}$ production following wounding in the tail bud of zebrafish larvae was visualized in vivo in the fluorescent reporter line, $\operatorname{Tg}(a c t b: H y P e r)$, that drives the expression of HyPer line using a $\beta$-actin (actb) promoter (26). This study demonstrated that a gradient of $\mathrm{H}_{2} \mathrm{O}_{2}$ after wounding was required for neutrophil recruitment to the site of injury. Visualization of $\mathrm{H}_{2} \mathrm{O}_{2}$ production within neutrophils after wounding was achieved using a zebrafish fluorescent reporter line, $\operatorname{Tg}(l y z: H y P e r)^{k a 4}$, that drives the expression of HyPer line using a lyz promoter (145).

\section{Additional Zebrafish Models to Study Neutrophil Function}

Several additional zebrafish transgenic and mutant lines have been developed to study neutrophil function. Defects in neutrophil trafficking have been modeled using four different transgenic lines. Humans with Warts, Hypogammaglobulinemia, Infections, and Myelokathexis (WHIM) syndrome have mutations in the chemokine receptor, CXCR4. A zebrafish model of WHIM syndrome, $\operatorname{Tg} 1(-8 m p x: c x c r 4 b-E G F P)^{u w m 3}$, was developed by expressing a truncated $\mathrm{Cxcr} 4 \mathrm{~b}$ protein tagged with a EGFP reporter in neutrophils using a $m p x$ promoter (146). A dominant-negative rac2 zebrafish line ( $\mathrm{Tg}$ (mpx:mCherry, rac2_D57N) $)^{z 307}$ ) was used to show that Rac2 was required for neutrophil migration to a tailfin injury (147). As described in the non-coding RNA section of this review, the microRNAs, miR$722(148,149)$ and miR-199 (150), are two additional zebrafish neutrophil trafficking mutants. Defects in Mpx function have been modeled in the "spotless" mutant, $m p x^{N L 144}$, which has a premature stop codon in the $m p x$ gene (151), and the durif mutant, $m p x^{g l 8 / g l 8}$, which has cis-acting point mutation in $m p x$ (145). Myeloperoxidase activity was absent in these mutants, as assayed using Mpx TSA and anti-nitrotyrosine staining (151). These models are complementary to Csf3r morphants that have depleted neutrophils $(144,152)$.

\section{ZEBRAFISH MODELS OF VIRAL INFECTION}

The zebrafish is a powerful model system for the study of virus infection and host immune response. Initial studies involved using the zebrafish to model fish viruses to develop strategies for mitigation, including fish virus vaccines. These studies often focused on critical factors like temperature and route of infection (immersion and different forms of injection) in order to replicate viral disease observed in other fish species. With time came the recognition that zebrafish viral infection models could also be used to study the host immune responses. These studies have become more sophisticated, moving from the realm of pathology and interferon and interferon-stimulated genes responses to more complex studies examining issues such as immune cell behavior. The zebrafish is uniquely positioned as a model in this regard due to the generation of various transgenic lines that label immune cells such as neutrophils and macrophages. As discussed previously, zebrafish possess numerous inherent advantages that make this type of investigation possible, including near 
transparency during the embryonic and larval periods of development, an array of forward and reverse genetics tools, and deeply sequenced genome. These advantages enable directed studies at the host-viral pathogen interface, where it is possible to answer questions about how cells like macrophages and neutrophils work to limit the spread of infection and regulate the inflammatory rheostat. Below is a summary of several viral models that have been developed in zebrafish, including fish viruses, human viruses that infect zebrafish, and xenograft models. Additional information about these and other viruses can be found in Table 5 .

\section{Fish Viruses for Heterologous Gene Expression}

Some of the earliest published virus studies performed in zebrafish used vesicular stomatitis virus (VSV) envelope containing glycoprotein (VSVG) pseudo-typed retroviruses. These efforts demonstrated that it was possible to stably transfer and express

TABLE 5 | Viruses studied in zebrafish.

\begin{tabular}{|c|c|c|c|c|}
\hline Virus Family & Virus & $\begin{array}{l}\text { Preferred } \\
\text { Host }\end{array}$ & Method(s) of Infection & Zebrafish or Human Receptor \\
\hline \multicolumn{5}{|c|}{ Group I: Double-stranded DNA Viruses } \\
\hline \multirow[t]{3}{*}{ Herpesviridae } & Cytomegalovirus (CMV) & Human & One-cell stage injection with pUL97 plasmid (153) & Human: OR14l1 (154) \\
\hline & Herpes simplex virus type 1 (HSV-1) & Human & $\begin{array}{l}\text { Inoculation by injection in the dorsal telencephalon } \\
\text { or olfactory bulb (155-159) }\end{array}$ & $\begin{array}{l}\text { Zebrafish: Hs3st4 (156) } \\
\text { Human: HS3ST4 }\end{array}$ \\
\hline & $\begin{array}{l}\text { Kaposi's sarcoma-associated } \\
\text { herpesvirus (KSHV or HHV8) }\end{array}$ & Human & Xenograft $(160)$ & $\begin{array}{l}\text { Zebrafish }{ }^{\#} \text { : Cd209, Itga3b, Itga5 } \\
\text { Human: heparin sulfate, CD209, ITGA3, } \\
\text { ITGA5 }\end{array}$ \\
\hline \multirow[t]{3}{*}{ Iridoviridae } & European sheatfish virus (ESV) & Fish & Immersion (161) & Unknown \\
\hline & $\begin{array}{l}\text { Infectious spleen and kidney necrosis } \\
\text { virus (ISKNV) }\end{array}$ & Fish & $\begin{array}{l}\text { Intraperitoneal injection, natural occurrence (162- } \\
\text { 164) }\end{array}$ & Unknown \\
\hline & Lymphocystis disease virus (LCDV) & Fish & Intraperitoneal injection (165) & Unknown \\
\hline \multicolumn{5}{|c|}{ Group III: Double-stranded RNA Viruses } \\
\hline Birnaviridae & $\begin{array}{l}\text { Infectious pancreatic necrosis virus } \\
\text { (IPNV) }\end{array}$ & Fish & $\begin{array}{l}\text { Vertical transfer (female), } \\
\text { natural occurrence, } \\
\text { immersion, intraperitoneal injection }(61,166,167)\end{array}$ & Unknown \\
\hline \multicolumn{5}{|c|}{ Group IV: Positive Sense Single-stranded RNA Viruses } \\
\hline Nodaviridae & $\begin{array}{l}\text { Betanodavirus (nervous necrosis virus) } \\
\text { (NNV) }\end{array}$ & Fish & $\begin{array}{l}\text { Intraperitoneal injection, natural occurrence, } \\
\text { immersion (168-171) }\end{array}$ & Zebrafish": Hspa8 \\
\hline Caliciviridae & Norovirus (NoV) & Human & Yolk sac injection, immersion (172) & Unknown \\
\hline Picornaviridae & Cyprivirus & Zebrafish & Natural occurrence (173) & Unknown \\
\hline \multirow[t]{2}{*}{ Togaviridae } & Chikungunya virus (CHIKV) & $\begin{array}{l}\text { Mosquito, } \\
\text { Human }\end{array}$ & Caudal vein, aorta $(94,117,174)$ & Unknown \\
\hline & Sindbis virus & $\begin{array}{l}\text { Mosquito, } \\
\text { Birds }\end{array}$ & Caudal vein, aorta $(175,176)$ & $\begin{array}{l}\text { Zebrafish": rpsa } \\
\text { Human: heparin sulfate, RPSA }\end{array}$ \\
\hline Flaviviridae & Zika virus & $\begin{array}{l}\text { Mosquito, } \\
\text { Human }\end{array}$ & Xenograft (177) & $\begin{array}{l}\text { Zebrafish": Axl } \\
\text { Human: AXL (178) }\end{array}$ \\
\hline Retroviridae & $\begin{array}{l}\text { Zebrafish endogenous retrovirus } \\
\text { (ZFERV) }\end{array}$ & Fish & Natural occurrence $(179,180)$ & Unknown \\
\hline \multicolumn{5}{|c|}{ Group V: Negative Sense Single-stranded RNA Viruses } \\
\hline \multirow[t]{4}{*}{ Rhabdoviridae } & Spring viraemia of carp virus (SVCV) & Fish & $\begin{array}{l}\text { Immersion, intraperitoneal injection, duct of Cuvier } \\
(51,57,61,108,181-183)\end{array}$ & Unknown \\
\hline & Snakehead rhabdovirus (SHRV) & Fish & $\begin{array}{l}\text { Immersion, intraperitoneal injection }(59,60,65 \text {, } \\
\text { 184) }\end{array}$ & Unknown \\
\hline & Piscine novirhabdovirus (VHSV) & Fish & Immersion, intraperitoneal injection (61, 185-188) & Unknown \\
\hline & $\begin{array}{l}\text { Infectious hematopoietic necrosis virus } \\
\text { (IHNV) }\end{array}$ & Fish & $\begin{array}{l}\text { Intraperitoneal injection, immersion, caudal vein, } \\
\text { aorta }(61,108,117,166,189-191)\end{array}$ & Unknown \\
\hline Orthomyxoviridae & Influenza A virus (IAV) & Human & Duct of Cuvier, swimbladder $(8,24,25)$ & $\begin{array}{l}\text { Zebrafish: Sialic acid (8) } \\
\text { Human: Sialic acid }\end{array}$ \\
\hline Flaviviridae & Dengue virus (DENV) & $\begin{array}{l}\text { Mosquito, } \\
\text { Human }\end{array}$ & Intraperitoneal injection (192) & $\begin{array}{l}\text { Zebrafish": Cd209, Rab5aa, Rab5ab, } \\
\text { Hspa5 } \\
\text { Human: CD209, RAB5A, HSPA5, }\end{array}$ \\
\hline Amnoonviridae & Tilapia lake virus (TiLV) & Fish & Immersion, intraperitoneal injection (53) & Unknown \\
\hline \multicolumn{5}{|c|}{ Group VII: Double-stranded DNA Viruses With an RNA Intermediate in Their Life Cycle } \\
\hline \multirow[t]{2}{*}{ Hepadnaviridae } & Hepatitis b virus (HBV) & Human & $\begin{array}{l}\text { One-cell stage injection with transgenic plasmid } \\
(193-195)\end{array}$ & $\begin{array}{l}\text { Zebrafish": Slc10a1 } \\
\text { Human: SLC10A1 }\end{array}$ \\
\hline & Hepatitis c virus (HCV) & Human & $\begin{array}{l}\text { One-cell stage injection with transgenic plasmid } \\
(194,196,197)\end{array}$ & $\begin{array}{l}\text { Zebrafish": Cd81a, Cd81b, Scarb1, } \\
\text { Cldn1, Oclna, Oclnb, Npc1l1 } \\
\text { Human: CD81, SCARB1, CLDN1, } \\
\text { OCLN, NPC1L1 }\end{array}$ \\
\hline
\end{tabular}

"Zebrafish ortholog identified using the Zebrafish Information Resource (ZFIN; https://zfin.org). 
genes in zebrafish via retroviral vectors (198-200), albeit at efficiencies lower than seen in human cells. Subsequently, the fish rhabdovirus IHNV [also formerly known as Oncorhynchus 1 novirhabdovirus now preferably known as the salmonid novirhabdovirus $(201,202)]$ and the aquatic birnavirus infectious pancreatic necrosis virus (IPNV) was shown to trigger infections in adult zebrafish following intraperitoneal injection and improve viral infection efficiency (166). In this study, it was noted that the infections particularly affected the head kidney, the principal site of hematopoiesis in the fishes, and that hematopoietic cells were affected. The results supported a role for this approach in complementing VSVG heterologous gene expression studies.

\section{Fish Viruses}

\section{Spring Viremia of Carp Virus (SVCV)}

The spring viremia of carp virus (SVCV), a species of virus belonging to the genus Vesiculovirus of the Rhabdoviridae family, is associated with acute infectious dropsy of carp and spring viremia of carp (181). Naturally occurring infections have been detected in numerous cyprinid species, and SVCV has been isolated from Nile tilapia and rainbow trout $(203,204)$. To better understand the disease process, a model in which adult zebrafish were challenged with SVCV by immersion was developed to mimic a natural route of infection (181). Zebrafish are typically maintained at $28^{\circ} \mathrm{C}-28.5^{\circ} \mathrm{C}$ to mimic their natural environment. Lethal SVCV infections most often occur at temperatures below $15^{\circ} \mathrm{C}$. In order to more closely model a natural infection, zebrafish were acclimated to lower temperatures and exposed by immersion to differing doses of SVCV. Several profound gross pathological changes that resembled natural infections were noted in zebrafish exposed to these lower temperatures; however, many of the histological changes that are typically noted in natural infections (e.g. edema, hemorrhage, inflammation, and necrosis) were not observed. This was attributed to the fact that the zebrafish were not able to mount a robust immune response at $15^{\circ} \mathrm{C}$ or $20^{\circ} \mathrm{C}$ as their natural environment is approximately $28^{\circ} \mathrm{C}$.

Another larval zebrafish model for SVCV infection was developed in which virus was injected into the systemic circulation via the caudal vein (57). Using this model, several ISGs were induced following SVCV infection, including rsad2, $m x a$, and $m x b$. Levraud et al (57) further adapted their SVCV model by introducing a morpholino-mediated, loss-of-function approach that knocked down Ifnphil expression. Survival to SVCV infection was improved in transgenic embryos that overexpressed ifnphil using beta-actin promoter. In addition, they identified Crfb1 and Crfb5 as subunits of the zebrafish IFN receptor complex, as Crfb1 and Crfb5 morphants lacked an interferon antiviral response to SVCV infection.

Lopez-Munoz et al. (182) developed an immersion model for SVCV infection using zebrafish larvae. They observed that $3 \mathrm{dpf}$ larvae exposed to SVCV at $26^{\circ} \mathrm{C}$ were susceptible to infection, with $50 \%$ survival seen between 3 - and 4-days post-infection (dpi). In addition, using their immersion strategy, they observed that SVCV failed to induce a robust antiviral IFN response, although there was evidence of a strong pro-inflammatory response with increased $i l 1 b$, tnfa, and lta expression. EspínPalazón et al. (55) applied a larval SVCV immersion model to determine that the pleiotropic pro-inflammatory cytokine Tnfa functioned to inhibit SVCV clearance by blocking autophagy in the host. Using the LC3-GFP autophagy transgenic line $[\mathrm{Tg}$ (CMV: EGFP-map1lc3b)] (205) and the zebrafish ZF4 fibroblast cell line, the authors found that Tnfa inhibits the formation of autophagosomes during viral infections. Libran-Perez et al. (206) further investigated the importance of autophagy in SVCV infection using the zebrafish larval infection model. They determined that exposure to palmitic acid, an antiinflammatory compound known to induce autophagy, could increase zebrafish survival and reduce viral load and replication.

There have been three studies aimed at understanding the effects of SVCV infection on the transcriptomes of adult zebrafish $(118,183,207)$. Encinas et al. (183) performed a microarray study in an effort to identify genes that participate in multiple pathways in the antiviral response and upon survival and were significantly up-regulated or down-regulated. They argued that specific targeting of these genes with candidate drugs could be an effective strategy in mitigating impacts on fisheries of SVCV. Wang et al. (118) performed a high-throughput RNA sequencing (RNA-Seq) experiment using brain and spleen tissue derived from SVCV-infected and control adult zebrafish. They identified 382 differentially expressed genes in the brain and 926 differentially expressed genes in the spleen. In each study, the authors identified differential expression of genes associated with inflammation and immunity. Valenzuela-Muñoz et al. (207) performed an RNA-Seq experiment comparing the long noncoding RNA (lncRNA) transcriptomes of kidney tissue from control and $\mathrm{rag}^{+/-}$heterozygous adult zebrafish following SVCV infection. As described later in this review, putative functional annotation of candidate lncRNA were assigned using Gene Ontology (GO) terms annotated to protein-coding genes within the proximity of the lncRNA (10 kbp up- or downstream). Using this approach, the authors identified lncRNA genes associated with adaptive immunity based on their differential expression in the $r a g 1^{+/-}$heterozygotes. In addition, they also identified lncRNA genes that could be linked to metabolic processes, including the activation of immune cells, and to positive regulation of TOR signaling, which may lead to the inhibition of autophagy. The authors noted that autophagy has been linked to both pro-viral and anti-viral responses.

\section{Infectious Spleen and Kidney Necrosis Virus (ISKNV)}

The infectious spleen and kidney necrosis virus (ISKNV) belongs to the genus Megalocytivirus in the family Iridoviridae. ISKNV and ISKNV-like viruses infect more than 50 marine fish species and impact fisheries of commercial value (208). In fact, natural infections of laboratory zebrafish have been noted (162). These zebrafish infections exhibited bloating, elevation of scales, and petechial hemorrhaging in adults. Xu et al. (163) developed an ISKNV adult zebrafish infection model using intraperitoneal injections of virus. Zebrafish infected with ISKNV exhibited mortalities and clinical symptoms reminiscent of natural infections, including elevation of scales and petechia. In addition, the virus induced cellular hypertrophy in the kidney and spleen. In a follow-up study comparing the course of ISKNV infection in Tetraodon nigroviridis and zebrafish, Xu et al. (209) 
showed significant induction of ifnphil and $\operatorname{tnfa}$ transcription in zebrafish, which is indicative of robust antiviral and proinflammatory responses to infection.

\section{Piscine novirhabdovirus (Formerly Oncorhynchus 2 Novirhabdovirus or Viral Hemorrhagic Septicemia Virus [VHSV] or Egtved Virus)}

Piscine novirhabdovirus belongs to the Novirhabdovirus genus of the Rhabdoviridae family and causes a prolific viral disease that afflicts over 50 freshwater and marine species in the northern hemisphere $(201,202)$. Novoa et al. (185) developed juvenile and adult zebrafish immersion and intraperitoneal injection models for piscine novirhabdovirus infection. They observed that adult zebrafish infected by intraperitoneal injection developed disease similar to that found in nature, with evidence of petechial hemorrhage, exophthalmoses, distended visceral cavities, and erratic swimming behaviors. Further, they observed in the kidney increased expression of gene transcripts associated with antiviral and pro-inflammatory responses, including tlr3, ifnphi1, mxa, ifng1, and tnfa. Novoa et al. (185) also demonstrated that a recombinant salmonid novirhabdovirus (IHNV) lacking an NV gene, but expressing piscine novirhabdovirus $\mathrm{G}$ gene, had dose-dependent protective effects for zebrafish in resisting piscine novirhabdovirus infection, as measured by a significant reduction mortality.

\section{Snakehead Rhabdovirus (SHRV)}

Snakehead rhabdovirus (SHRV) belongs to the Novirhabdovirus genera of the family Rhabdoviridae and is closely related to the other commercially significant viruses IHNV and VHSV. We have previously published a comprehensive characterization of SHRV infection in zebrafish (59). Our laboratory group developed and applied embryonic and adult zebrafish models for SHRV infection to address questions related to the host immune and inflammatory response to infection $(59,60,65)$. Zebrafish between $24 \mathrm{hpf}$ and $30 \mathrm{dpf}$ were susceptible to infection by immersion, while adult zebrafish could only be infected by intraperitoneal injection. Infected zebrafish presented with petechia, abdominal redness, and erratic swim behaviors. Histological examination of embryonic and juvenile fish revealed evidence of inflammation, including pharyngeal epithelium and liver necrosis and congestion of the swim bladder by cellular debris. There was also evidence of monocyte accumulation in the infected areas, which is indicative of inflammation. Adult fish infected with SHRV exhibited more localized effects closer to the site of infection, including evidence of inflammation with edema, petechia, and fluid and immune cell accumulation in the abdomen. In addition, SHRV infection by immersion induced expression of antiviral ifnphil and $m x a$ transcripts. In another study, Phelan et al. (65) determined that SHRV upregulated expression of the immune genes traf6 and tlr3 and slightly downregulated the expression of irak4 in both embryonic and adult zebrafish. Gabor et al. (60) showed that the overexpression of a full-length Mda5 was protective against SHRV infection, while overexpression of a dominant-negative Mda5 receptor (with a CARD domain deletion) could increase SHRV mortality. Kortum et al. (184) applied the adult SHRV infection model to characterize its effects on polymeric immunoglobulin (Ig) receptor (pIgR) expression. pIgR expression is thought to be regulated by Tlr3 and Tlr4 signaling and to link aspects of the innate immune response to the adaptive immune response (210). Upon SHRV infection, Kortum et al. (184) observed that pigr and pigrl transcripts were reduced, leading to speculation that SHRV suppresses the immune response, at least in part, through this mechanism.

\section{Zebrafish Picornavirus-1 (ZfPV-1)}

Recently, evidence for a natural picornavirus infection in the zebrafish gut was detected in a viral metagenomics analysis of zebrafish gut tissue (173). In situ hybridization revealed infection of the apical surfaces of enterocytes, as well as near the mucosal layer and within the lumen of the intestine. While AB zebrafish infected with ZfPV-1 were asymptomatic, the virus appears to be widespread in research facilities, with $56 \%$ of the 41 institutions tested exhibiting evidence of infection within the fish populations. The prevalence of $\mathrm{ZfPV}-1$ in wild populations has not been determined. Development of a picornavirus model that can infect zebrafish naturally and not trigger symptoms has the potential to reveal novel insights into the underpinnings of the host-pathogen interaction in a low-level infection. It may be possible to gain an understanding of the role these viruses play in dysregulating immune and inflammatory responses over time, including in the presence of secondary infections, and in affecting embryonic development. In addition, a zebrafish picornavirus model could be applied to test the immune robustness of different zebrafish strains as well as the importance of various immune responsive genes.

As described, there are numerous advantages to modeling fish viruses in the zebrafish. The ability to have an easily maintained, relatively low cost, teleost model to study viral infection makes it possible to study an array of research questions. There are several challenges that need to be overcome in order to model viral disease, including determining the appropriate life stage, potential issues with viral tropism, and especially difficult hurdles related to temperature. Nevertheless, there is now a considerable body of literature demonstrating the usefulness of the zebrafish models in the study of fish viruses and immune response. It is particularly noteworthy that many of these viruses can be modeled during the embryonic and larval periods. This ability to infect embryonic and larval fish enables researchers to ask far more precise questions, particularly in the realm of hostvirus interaction and immune response. Future studies should take advantage of these developing models to answer critical questions related to vertebrate immune responses to viruses that are universal and conserved across all species.

\section{Human and Mammalian Viruses}

Zebrafish possess many of the same receptors required by human and other mammalian viruses for entry and infection (Table 5). The following summarizes some of the human virus research that has been conducted in the zebrafish model. These studies highlight the flexibility of the zebrafish model, particularly with 
regard to its ability to acclimate and then be infected by viruses that are typically most virulent in temperature ranges more conducive to humans and mammals.

\section{Chikungunya Virus}

Chikungunya virus (CHIKV) is a single-stranded, positive-sense Alphavirus that causes acute, febrile illnesses accompanied by severe arthralgia (211). CHIKV is a mosquito-borne virus endemic to Africa, Asia and the Indian subcontinent, although there have been outbreaks in other parts of the world, including in the regions of the Americas (212). Palha et al. (94) developed a larval zebrafish model for CHIKV infection. Using a GFP-labeled CHIKV, the authors observed the development of a systemic infection that largely resolved by 4 days post-infection (dpi). Interestingly, CHIKV infections persisted in the brain parenchyma until at least $7 \mathrm{dpi}$. CHIKV induced a powerful type I interferon response, as measured by ifnphil expression, that was largely mediated by neutrophils and hepatocytes. The role neutrophils played in producing this antiviral ifnphil response was particularly intriguing because their function in viral infections has not been fully appreciated. These findings were bolstered by experiments that compared the relative importance of macrophages and neutrophils in containing CHIKV infections. Palha et al. (94) observed that reductions in neutrophil populations (induced by morpholino knockdown of Csf3r) made zebrafish more susceptible to CHIKV infection, while macrophage depletion by a drug-inducible cell ablation system led to only a modest increase in disease severity.

Briolat et al. (117) performed microarrays on larval zebrafish that had been infected with either IHNV or CHIKV. Each of these viruses has different disease kinetics and induce differing type I interferon response. While IHNV stimulates a milder type I interferon response, CHIKV induces a far more robust expression. Using the microarray approach, the authors identified a suite of zebrafish ISGs that they could compare to human studies. With this information, Briolat et al. (117) identified ISGs that are conserved across vertebrate species.

\section{Sindbis Virus}

Like CHIKV, the Sindbis Virus (SINV) is an Alphavirus capable of neuroinvasion. Passoni et al. (175) developed a larval SINV infection model in the zebrafish and observed that the virus could infect multiple organs and replicate throughout the larvae. Further, they established the means by which CHIKV and SINV entered the central nervous system. Based on the data they collected, Passoni et al. (175) speculated that CHIKV enters the CNS by infecting the brain microvasculature endothelial cells at the blood-brain barrier and that SINV enters the CNS through axonal transport via the peripheral nerves.

Boucontet et al. (176) observed that larval zebrafish infected with SINV exhibited increased mortality when infected secondarily with the bacterium Shigella flexneri. The authors also noted increased bacterial burdens in those animals that were infected with SINV first and $S$. flexneri second. The initial viral infection induced expression of antiviral ifnphi1, pro-inflammatory tnfa and illb, and antiinflammatory Il10 transcripts. It also affected neutrophil populations, function, and behavior. Specifically, Boucontet et al.
(176) noted fewer neutrophils and more dying neutrophils in larvae that had been infected with SINV and then S. flexneri. Interestingly, they noted an increase in neutrophils by 120 hpi when zebrafish were infected with SINV. The authors speculated that the SINV infection triggers an IFN polarization that renders affected cell populations unable to mount antibacterial responses. They also observed the neutrophils exhibited defects in recruitment to areas of infection, and they attributed this finding to the upregulation of il10 that was observed. Taken together, these data indicate an important role for neutrophils in containing secondary infections following SINV infections and offer this superinfection model as a means to test these phenomena.

\section{Dengue Virus}

Dengue virus (DENV) is a single-stranded, positive-sense, mosquito-borne Flavivirus that can induce a broad range of manifestations in infected humans, from asymptomatic to severe flu-like. Recently, Balkrishna et al. (192) described an adult zebrafish model for Dengue virus serotype 3 (DENV-3) infection. The authors collected serum containing DENV-3 from human subjects and then performed intramuscular injections of serum into adult zebrafish that served as carriers to propagate the virus. After 14 days, serum from infected zebrafish was harvested, diluted, and injected intramuscularly into secondary adult zebrafish, which served as the study subjects. Using a qPCR-based approach to measure DENV-3specific transcripts, Balkrishna et al. (192) observed a viral load that was sustained through 15 days post-injection. Histological analysis of the liver indicated necrosis, increased numbers of inflammatory cells, and increased presence of erythrocytes. Blood smears indicated increasing numbers of leukocytes over the course of infection, decreasing numbers of erythrocytes, and decreased numbers of platelets, which is commonly seen in human DENV infections. Close inspection of caudal fins revealed evidence for DENV-induced hemorrhage that was not seen in control groups. Further, increases in the expression of ang2, a pro-angiogenic gene and indicator of inflammation, and ccl3, a chemokine, were noted. The ayurvedic herbal drug, Denguenil, was shown to limit the effects of DENV-3 infection in this zebrafish model in a dose-dependent manner, as evidenced by decreased levels of necrosis, reduced numbers of inflammatory cells, and decreased levels of erythrocytes in the liver; decreased number of leukocytes, increased numbers of erythrocytes, and decreased numbers of platelets in blood smears; diminished evidence of hemorrhage in caudal fins; and decreases in the levels of ang 2 and $c c l 3$ transcripts.

\section{Human Noroviruses}

Human noroviruses are single-stranded, positive-sense, nonenveloped RNA viruses belonging to the family Caliciviridae and are the primary causes of viral gastroenteritis. Van Dycke et al. (172) recently described a larval zebrafish model for human norovirus infection. Zebrafish at $3 \mathrm{~d}$ post-fertilization were subjected to yolk injections of human norovirus collected from the stool of human test subjects. A concurrent set of experiments with mouse norovirus was conducted, but it was determined the mouse noroviruses could not cause infections. The authors 
observed that human norovirus replicated in zebrafish, as detected by qPCR assays designed to detect viral RNA copies. These data were supported by ELISA, in which evidence of increased viral antigens was observed. Human norovirus replication was detected by immunohistochemistry in both the intestine and caudal hematopoietic tissue of the larval zebrafish. These findings supported the idea that there is a dual tropism for human noroviruses in zebrafish. Infections with human norovirus also induced antiviral responses in the zebrafish, as evidenced by significant increases in the expression of ifnphil, $m x a$, and $r s a d 2$ transcripts relative to controls. Zebrafish infected with the human norovirus exhibited significant reductions in viral load following exposure by immersion to the antiviral compound 2'-C-methylcytidine (2CMC) (as measured by EIA). These findings demonstrated the utility of this infection model for testing antiviral drugs.

\section{Herpes Simplex Virus - Type 1}

Herpes simplex virus - type 1 (HSV-1) is a double-stranded DNA virus that belongs to the Alphaherpesviridae subfamily. In humans, HSV-1 may be transmitted by saliva or other bodily secretions. It is most often associated with cold sores, but can also cause an array of other herpetic lesions, including herpetic sycosis, herpes gladiatorum, and herpetic whitlow (213). Burgos et al. (155) developed an adult zebrafish model for HSV-1 infection. Following intraperitoneal injections, zebrafish were monitored for the presence of HSV-1 DNA. Between 1- and 4-days post-infection, zebrafish experienced active infection, as demonstrated by the presence of HSV-1 DNA. In addition, histological examination of zebrafish injected with HSV-1 demonstrated that there was a concomitant inflammatory response, even at sites distal to the site of injection. There were indications of degeneration of secondary oocytes and hemorrhage within the muscle tissue. The authors also noted tropism for neuronal tissue by the HSV-1.

Human heparan sulfate modifying enzyme 3-Osulfotransferase-3 (3-OST-3) functions as a cellular receptor for HSV-1 infection. Zebrafish express multiple isoforms of (3-OST) (214). Several studies were performed in which the zebrafish 3OST isoforms 3-OST-2, 3-OST-3, and 3-OST-4 were heterologously expressed in hamster $\mathrm{CHO}-\mathrm{K} 1$ cells. $\mathrm{CHO}-\mathrm{K} 1$ cells are normally resistant to HSV-1 infection; however, when the zebrafish 3-OST isoforms 3-OST-2, 3-OST-3, and 3-OST-4, and 3-OST-6 were heterologously expressed, these cells became sensitive to HSV-1 infection (156, 215-217). Interestingly, both zebrafish 3-OST-2 and 3-OST-4 are widely expressed in the central nervous system. Because of this, zebrafish may represent an ideal model in which to study effects of HSV-1 infection on the central nervous system and test potential therapeutics (156).

$\mathrm{Ge}$ et al. (157) demonstrated that HSV-1 could infect zebrafish at different larval stages from 48-96 hpf. They noted that HSV-1 infection triggered potent antiviral responses that included the upregulation of IFN and ISGs, including isg15 and rsad2. While they demonstrated that the antiviral response that was generated was mediated through a Sting1-mediated cytosolic DNA sensing pathway initiated by Dhx9 and Ddx41 orthologues, they surprisingly found that cyclic GMP-AMP synthase (cgas) was not required for Sting1 signaling. These data support a mechanism by which zebrafish can mount a robust Stingmediated inflammatory response, as has been demonstrated in other models (218).

\section{Hepatitis Viruses}

Similar to DENV, hepatitis C virus (HCV) is a single-stranded, positive-sense RNA virus belonging to the Flaviviridae family of viruses. In addition to causing hepatitis, or inflammation of the liver, persistent HCV infections can lead to hepatocellular cancer. To date, no vaccine has been developed to prevent HCV infection. In vitro $\mathrm{HCV}$ studies had proven difficult until the development of subgenomic replicons that replicate autonomously (12, 219). Ding et al. (196) recently adapted a subgenomic replication scheme for use in zebrafish to model HCV replication in a live animal. In their study, the authors demonstrated by the presence of $\mathrm{HCV}$ transcripts that replication occurred. In addition, they observed that $\mathrm{HCV}$ replication could be inhibited by the drugs ribavirin and oxymatrine. Ding et al. (196) also noted expression of the HCV subgenome transcripts in the zebrafish liver and that this disrupted the expression of homologous genes similarly affected in human $\mathrm{HCV}$-infected liver cells. These data indicated that this zebrafish model effectively recapitulates aspects of HCV infection and may be useful in better understanding the effects of HCV-triggered inflammation on transformation to hepatocellular cancer

Li et al. (220) modified this HCV model to restrict its expression to the zebrafish liver. Using this zebrafish liverspecific HCV subgenomic replication model, the authors observed opposing effects on autophagy when either human ATG10 or ATG10S was overexpressed. Specifically, ATG10 overexpression triggered amplification of the HCV-subgenomic replicons, while ATG10S overexpression caused their degradation. These data, coupled with data from experiments using the autophagy inhibitors 3MA and CQ, provide evidence for how autophagy may influence aspects of HCV replication. Because of the linkages between autophagy and inflammation (221), this model may facilitate studies aimed at understanding these processes in the context of $\mathrm{HCV}$.

\section{Influenza A Virus (IAV)}

We have described zebrafish models for IAV infection that resemble human disease $(8,24)$. We demonstrated that zebrafish possess the $\alpha$-2,6-linked sialic acid residues on their cells that provide IAV viruses a way to bind, attach, and enter cells. We showed that two different strains of IAV $(\mathrm{A} / \mathrm{PR} / 8 / 34[\mathrm{H} 1 \mathrm{~N}]$ and X-31 A/Aichi/68 [H3N2]) could infect, replicate, and cause mortality when injected into the circulatory system of a larval zebrafish. Using a recombinant IAV strain carrying a GFP reporter (NS1-GFP) (222), we demonstrated the progression of an infection that could be monitored by fluorescence microscopy. In addition to being a model for disseminated infection, we also developed a model for localized IAV infection using the swimbladder $(8,24)$, which is considered the functional analogue of the human lung in fish (223). Zebrafish infected with IAV produce strong antiviral responses, as measured by increased expression of ifnphil and mxa. Zebrafish also exhibit strong pro-inflammatory responses to IAV infection, with increases in the expression of $i l 1 b$ and cxcl8 transcripts observed, 
increased $\mathrm{NF \kappa B}$ activation as noted in $\operatorname{Tg}(6 x H s a . N F \kappa B:$ EGFP) transgenic fish, and extensive damage to zebrafish muscle fibers, with neutrophils recruited to sites proximal to the unanchored ends of some fibers (25).

\section{Zika Virus (ZIKV)}

The Zika virus (ZIKV) is a positive sense, single-stranded, enveloped RNA virus belonging to the Flaviviridae family (224). ZIKV is transmitted to humans primarily by some types of Aedes mosquitoes (A. aegypti and A. albopictus), but there are other modes of transmission, including through sexual intercourse, laboratory exposure, blood transfusion, and from mother to fetus during the pre- and peri-natal periods. Most ZIKV infections trigger mild symptoms, including rash, fever, joint pain, and/or non-purulent conjunctivitis; however, ZIKV infections during pregnancy can have profound effects on the developing fetus' nervous system. These may include congenital Zika syndrome (CZS), which is characterized by severe microcephaly accompanying the fetal brain disruption sequence (FBDS), as well as other brain and ocular defects and congenital contractures (225).

Ayala-Nunez et al. (177) developed a xenotypic system in their study aimed at understanding the role infected human monocytes play in disseminating ZIKV to the neural cells. In their model, they labeled human CD14+ monocytes with the dye CellTrace Yellow and injected them via the duct of Cuvier into the circulation of $48 \mathrm{hpf}$ zebrafish embryos. By performing live imaging, the authors observed that monocytes infected with ZIKV exhibited increased capacity for transmigration. They also noted that monocytes exposed to ZIKV were more prone to arrest in zebrafish vessels and suggested that this behavior may facilitate attachment to the endothelial cells of the blood vessel. These data support a likely role for the microenvironment in mediating transmigration. We speculate that this zebrafish model could be applied to study the effects an inflammatory microenvironment has on monocyte transmigration when infected with ZIKV. It is worthwhile to note that ZIKV infects human cells that are cultured at temperatures $10^{\circ} \mathrm{C}$ higher than zebrafish embryos and the cooler temperature may alter function of the ZIKV-infected human monocytes. A follow-up experiment in the same study was performed using a transwell migration assay system in which infected human monocytes were added to a well containing a porous membrane layered with cells mimicking the blood brain barrier. Under the transwell, neural organoids were added. In this experiment, more ZIKVinfected monocytes were observed to migrate across the membrane than control monocytes. Further, the authors noted infection of the neural organoids by ZIKV, which indicated viral dissemination by the monocytes.

These research studies, coupled with the studies conducted with fish viruses, demonstrate the strength of the zebrafish model and highlight several of its attributes, including its fully sequenced genome, which allows for the identification of putative viral receptors that can often be inferred based on homology. The zebrafish model has been aided by the development of a variety of fluorescent reporter lines that label immune and other cells. Regarding host-virus interactions, there has been a wealth of knowledge garnered through the development of alternative vertebrate model systems. Nevertheless, the zebrafish model allows researchers to investigate questions often more difficult to answer in these other models. As an example, alternative vertebrate models for influenza A infection exist, including those in mice, guinea pigs, cotton rats, hamsters, ferrets, and macaques $(226,227)$. Each have distinct advantages and disadvantages, but none is ideal. For example, the mouse model is limited by the fact that many human influenza A viruses are unable to infect it due to differences in the viral receptors they possess. On the other hand, the ferret model possesses similar viral receptors to humans and mimics the viral kinetics most closely, but it is difficult to use due to its relative size and cost of husbandry, in addition to a lack of reagents and methods. When applied to appropriate research questions, zebrafish can have real advantages over mice, ferrets, and these other vertebrate models, particularly in areas related to neutrophil and macrophage biology. Using the zebrafish model, it is possible to track individual cells and ascertain their role in host defense and host inflammation using the full array of transgenic reporter lines and other reagents available. As described above, in each of the other human viruses tested, the zebrafish model has been utilized to make significant contributions. It is important for researchers interested in modeling virus infections to recognize the strengths and limitations of their respective models. Cross-model approaches have the potential to illuminate areas of host-virus biology that cannot be observed otherwise.

\section{NEUTROPHILS AND HYPERINFLAMMATORY TISSUE DAMAGE}

Tissue damage can be caused by neutrophils when they fail to properly resolve inflammation. This can occur when neutrophils become over-activated and/or the number of neutrophils at the site are not reduced. In this uncontrolled response, neutrophils and macrophages recruited by these cytokines can destabilize the vasculature and damage tissues as they migrate to the site of infection as shown in a mouse model of IAV infection (228). Reduction of the number of neutrophils at a site of inflammation can occur by pyroptosis and reverse transendothelial migration. Failure to reduce the number of neutrophils at the site of inflammation can result in tissue damage (229). The inflammatory cytokine, illb, has been shown to have a critical role in prolonged inflammation in the zebrafish notochord that cannot be infiltrated by macrophages and neutrophils during early stages of bacterial infection (230). Knockdown of Il1b was used to demonstrate that Illb was required for the recruitment of neutrophils to the notochord. The same study also described how neutrophils can degranulate without having direct interaction with a pathogen. A subsequent study identified how neutrophilgenerated ROS cleared bacterial infection of the notochord even though neutrophils cannot infiltrate the notochord (144).

Damage to skeletal muscle was observed in a zebrafish model of IAV infection (25). By 24 hours post infection, zebrafish embryos were observed to have mild muscle degeneration with sarcolemma damage and defects in extracellular matrix adhesion. 
Confocal imaging of IAV-infected $\operatorname{Tg}(m p x: E G F P)$ showed that neutrophils localized to sites of fiber damage. Muscular degeneration phenotypes observed in the zebrafish model of Duchenne Muscular Dystrophy, $d m d^{\text {ta222a/ta222a }}$, were found to be exacerbated following IAV infection.

\section{TRANSCRIPTIONAL PROFILING TO IDENTIFY STAGES OF HYPERINFLAMMATORY RESPONSE}

High-throughput RNA sequencing (RNA-Seq) of bulk tissues has begun to be applied to study zebrafish models of viral infection. The response to SVCV infection in zebrafish was characterized by RNA-Seq in the brain and spleen tissues (118). Levraud et al. (174) used RNA-Seq to characterize the response to CHIKV infection following morpholino-mediated knockdown of Crfb1 and Crfb2. Another important aspect of this study was identifying 97 ISGs that had human orthologs previously identified as ISGs in other studies. Another study of SVCV infection profiled gene expression in kidneys at $24 \mathrm{hpi}$ in six-month old adult zebrafish with and without an impaired adaptive immune system by comparing heterozygous $\mathrm{rag}^{+/-}$and wild-type zebrafish (207). Sixteen proviral insertion sites in Moloney murine leukemia virus (PIM) kinases were recently found to have increased gene expression following SVCV infection in adult zebrafish kidneys at $24 \mathrm{hpi}$ using RNA-Seq, and that three pan-PIM kinase inhibitors blocked viral entry (231). As several zebrafish fluorescent reporter strains have been used for FACS to isolate macrophages or neutrophils for cell-specific functional analysis $(38,48)$, RNA-Seq could be applied to characterize these FACS sorted cell populations following virus infection. Single cell RNA-Seq (scRNA-Seq) has been applied to study embryonic development (232) and tissue regeneration (233) in the zebrafish. This technology should prove valuable in characterizing the inflammatory response to viral infection and potentially identify genes that differentiate phagocytes between various states of activation.

\section{ROLES OF NON-CODING RNA}

Genes function together in complex networks with multiple layers of genetic regulation that include both protein coding and nonprotein coding genes. In the Ensembl annotation of the zebrafish genome [Ensembl version 103 annotation of GRCz11 (234)], there are 25,592 protein-coding genes, 3,227 small non-coding, and 3,278 long non-coding genes. These non-coding genes lack long open reading frames, and map to intergenic regions, introns, or antisense to protein-coding genes. Studies of non-coding genes in human and mouse have demonstrated important cis- and/or trans-regulatory roles in immune function as summarized below.

Long non-coding RNAs (lncRNAs) have transcripts that exceed $200 \mathrm{bp}$, and are classified based on their genomic location and orientation. Classes of lncRNAs include long intergenic RNA (lincRNA), antisense, bidirectional, intronic, and enhancer- associated RNAs. Diverse functions of lncRNAs have been described. They can function as both positive and negative regulators at the DNA, RNA or protein level in cis and trans. Some lncRNAs function in the nucleus to interact with chromatin, while others interact with RNAs or proteins in the cytoplasm. An example of a cis-regulatory lncRNA is the mouse antisense lncRNA, Gm14023 (235). Gm14023, is antisense to Illa and functions to regulate the recruitment of RNA polymerase II to the Illa promoter following TLR ligand stimulation (235). Examples of trans-regulatory lncRNAs include the mouse antisense lncRNA, Ttc39aos1, that was originally named, $\ln c R N A-E P S$ (236). A mouse knockout of Ttc39aos1 and gain-of-function experiments showed that it was required to control the expression of immune response genes in macrophages (236). An example of a lncRNA that has been shown to function in both cis and trans is the mouse long intergenic RNA, Ptgs2os2, that was originally named, $\ln c R N A-C o x 2$ (237). Knockdown of Ptgs2os2 by shRNA showed that the expression of proinflammatory genes (including Tlr1, Il6, and Il23a) was decreased, and chemokines (Ccl5 and Cx3cl1), chemokine receptors (including Ccr1), and interferonstimulated genes (including Irf7, Oas1a, Oas1l, Oas2, Ifi204 and Isg15) were upregulated (237).

A study of the role of the adaptive immune system in response to SVCV in zebrafish kidneys found that 12,165 putative lncRNAs were expressed (207). The study examined lncRNA candidates by looking for differentially expressed protein coding genes that mapped to within $10 \mathrm{kbp}$ of the lncRNA and testing for enriched Gene Ontology terms. Among putative lncRNAs investigated were two lncRNAs that map adjacent to rag1 and rag2 in the zebrafish genome, suggesting a regulatory role.

MicroRNAs are negative regulators of gene expression that have been shown to be required for zebrafish immune function $(49,148,149$, 238) in addition to embryonic development (239), and tissue regeneration $(240,241)$. Downregulation of both miR-722 $(148,149)$ and miR-199 (150) have been shown to be required for neutrophil migration in zebrafish. Studies of zebrafish with systemic Pseudomonas aeruginosa PAK strain infection showed that neutrophil expression of miR-722 was required for regulating the inflammatory response through Rac2 (149). Overexpression of miR-722 in the $\operatorname{Tg}($ lyz:

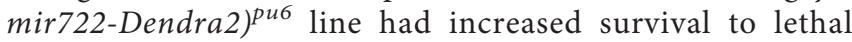
inflammation caused by acute Pseudomonas infection. A screen of several microRNAs showed that miR-199-3a was required for neutrophil migration (150). Using the neutrophil-specific overexpression line, $\operatorname{Tg}(\text { lyz:mir722-Dendra2 })^{p u 19}$, it was shown that miR-199 regulates cyclin-dependent kinase 2 ( $c d k 2$ ). Hypermaturation of neutrophils and defective interferon signaling was observed in miR$142 \mathrm{a}$ and miR-142b double-knockout zebrafish (49). Genes differentially expressed in miR-142 double-knockout included stat1a and irf $1 b$. The neutrophil inflammatory response to tailfin injury was shown to be regulated by miR-223 by regulating nuclear factor (NFKB) signaling (238). Using miR-223 knockout and multiple miR-223 transgenic lines, it was shown the expression from both neutrophils and the basal and apical epithelium functioned to negatively regulate neutrophil recruitment. NFKB activity, visualized using the $\mathrm{Tg}$ $(6 x H s a . N F \kappa B: E G F P)^{n c 1}$ line, was upregulated following tailfin injury in miR-223 mutants. The contribution of miR-233 expression in neutrophils was studied using the $\operatorname{Tg}(\text { lyz:RFP-mir223) })^{p u}$ along 
with a transgenic line that expressed a miR-223 sponge in apical epithelial cells, $T g(k r t 4: R F P-b s m i r 223)^{p u 12}$. Specific miR-223 targets identified included culla, cul1b, traf6, and tab1.

MiRNAs are important candidate genes to study in the inflammatory response to virus infection, but miRNAs conserved with humans should be prioritized. MiRNAs are highly conserved across animal taxa in an evolutionary context (242). One of the first miRNAs discovered, let-7, is conserved across metazoa, but other miRNAs, such as miR-722, are only found in teleost fish. MiRNAs are organized into families based on their seed sequence that is used to determine targets. Once a miRNA family evolves, it is rarely lost during evolution. As described in MiRGeneDB (243), the roundworm (C. elegans) has 145 miRNAs in 90 families, the zebrafish has 390 miRNAs in 113 families, the mouse has 447 miRNAs in 224, and humans have 556 miRNAs in 267 families. The number of miRNA families correlate with complexity that is estimated by the number of distinct cell types (242). In addition, the complexity of immune systems across metazoa correlates with the number of miRNA families. Studies of miRNAs in the response to viral infection in the zebrafish are promising as a total of 79 families, including miR199, are conserved between zebrafish and humans (Figure 3).

\section{DISCUSSION}

Modeling viral infection in the zebrafish and other fishes have provided valuable information about the inflammatory response and other host-virus interactions that are complementary to other model systems. Zebrafish models of viral infection take advantage of the strengths of the model that include genetic tools and reporter lines that allow for in vivo imaging. One aspect of the inflammatory response to viral infection that needs additional study is the contribution of neutrophils. As summarized in this review, several existing zebrafish models have been designed to study neutrophil function. Some of these tools have begun to be the applied to study viral infection as the role of the inflammatory response of neutrophils during viral infection is largely unknown.

We hypothesize that there is an immunologic tipping point during viral infection between the beneficial antiviral activity and tissue damaging hyperinflammatory response of neutrophils (Figure 4). ROS generated by virus-infected cells may initiate neutrophil chemotaxis during an IAV infection. By recruiting neutrophils to areas of virus-induced tissue damage through the formation of $\mathrm{H}_{2} \mathrm{O}_{2}$ gradients, these neutrophils may then be retained at the site because the high ROS levels suppress cell motility. ROS play critical roles in the immune response, serving both as indicators of immune dysregulation and as mediators of various immune processes, including neutrophil migration. The roles of ROS in viral infection have not been definitively identified. In addition, type I and type II IFN together reduce neutrophil migration and limit hyperinflammation during IAV infection. The connections linking the effectors of ROS production, however, like the NADPH oxidase and myeloperoxidase, as well as the mechanisms driving the suppression of neutrophil migration by interferon signaling, are unknown. Our hypothesis is that neutrophils, while controlling an IAV infection, trigger excessive inflammation through mechanisms involving ROS production and type I IFN signaling.

The importance of neutrophils in the innate response to viral infection is an ongoing subject of controversy. Zebrafish models of virus infection are uniquely poised to enable characterization of the molecular signals that stimulate neutrophils to migrate in vivo and elucidate pathways that lead to generation of ROS and other mediators of inflammation in the antiviral response. Furthermore, studies that model human viruses in zebrafish, such as IAV, have the potential to provide unique insight regulating neutrophil function during the inflammatory and

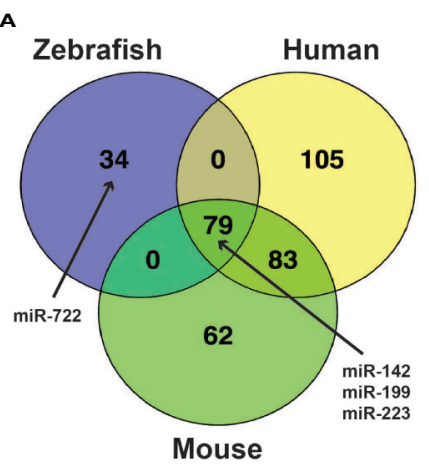

B

Origin of 79 Conserved miRNA Families

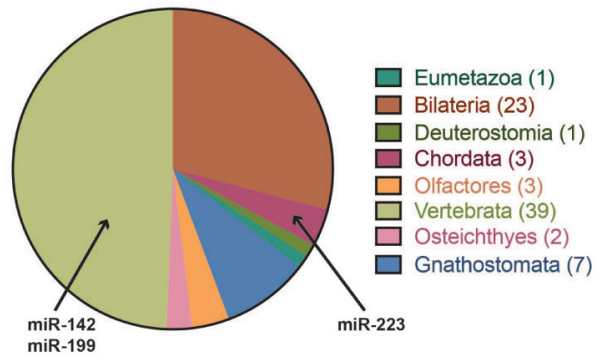

FIGURE 3 | Overlap among miRNA families in zebrafish, mouse, and human genomes. (A) 79 miRNA families are conserved among zebrafish, mouse and human genomes, including miR-142, miR-199 and miR-223. 34 miRNA families are found in the zebrafish, but not in the mouse or human genome. One of the 34 miRNA families is miR-722 which was shown to regulate zebrafish neutrophil migration. 62 miRNA families are found in the mouse, but not in the zebrafish or human genome. 105 miRNA families are found in the human genome, but not in the zebrafish or mouse genome. 83 miRNA families are conserved between the mouse and human genomes that are not found in the zebrafish genome. (B) The origin of the 79 conserved miRNA families are labeled by the last common ancestor for Eumetazoa, Bilateria, Deuterostomia, Chordata, Olfactores, Vertebrata, Osteichthyes, and Gnathostomata with the number of families shown in parentheses. Two of the 79 miRNAs are miR-199 and miR-223 that have roles in neutrophil function. The node of origin for miR-142 and miR-199 is Vertebrata, and Gnathostomata for miR-223. 

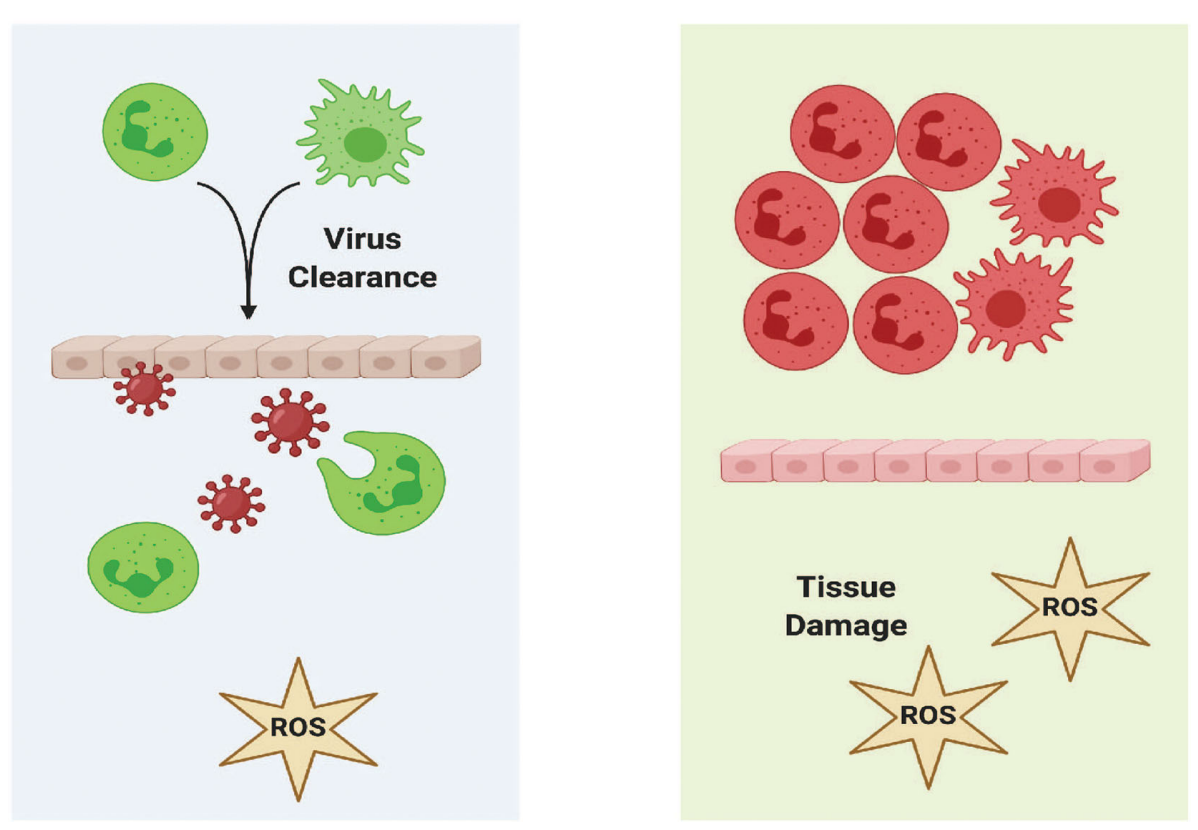

FIGURE 4 | Immunological Tipping Point in The Inflammatory Response to Virus Infection. A balance between the role of antiviral and hyperinflammatory responses by neutrophils must be maintained to avoid tissue damage during infection by IAV or other viruses. We hypothesize that the modulation of ROS is a central factor in regulating the response to virus infection.

antiviral responses. One advantage of the zebrafish model is the potential to screen small molecules to identify potential candidate therapeutics at relatively low cost. One example was demonstrating that the neuraminidase inhibitor, Zanamivir, extended survival in our zebrafish model of IAV infection (8). These advances may inform the development of new treatments that modulate the inflammatory response to viruses like IAV.

\section{AUTHOR CONTRIBUTIONS}

CS and BK developed the overall outline of the manuscript. B-LS created all tables and Figures 1, 2 and 4. BK created Figure 3. CS, B-LS, CK, PM and BK wrote the manuscript. All authors contributed to the article and approved the submitted version.

\section{REFERENCES}

1. Betakova T, Kostrabova A, Lachova V, Turianova L. Cytokines Induced During Influenza Virus Infection. Curr Pharm Des (2017) 23:2616-22. doi: $10.2174 / 1381612823666170316123736$

2. Brandes M, Klauschen F, Kuchen S, Germain RN. A Systems Analysis Identifies a Feedforward Inflammatory Circuit Leading to Lethal Influenza Infection. Cell (2013) 154:197-212. doi: 10.1016/j.cell.2013.06.013

3. Clark IA. The Advent of the Cytokine Storm. Immunol Cell Biol (2007) 85:271-3. doi: $10.1038 /$ sj.icb.7100062

4. Webb BJ, Peltan ID, Jensen P, Hoda D, Hunter B, Silver A, et al. Clinical Criteria for COVID-19-associated Hyperinflammatory Syndrome: A Cohort Study. Lancet Rheumatol (2020) 2:e754-63. doi: 10.1016/S2665-9913(20)30343-X

5. Cron RQ, Schulert GS, Tattersall RS. Defining the Scourge of COVID-19 Hyperinflammatory Syndrome. Lancet Rheumatol (2020) 2:e727-9. doi: $10.1016 /$ S2665-9913(20)30335-0

\section{FUNDING}

The authors were supported by the National Institute of Allergy and Infectious Diseases of the National Institutes of Health under grant number R15 AI131202. BK was also supported by an Institutional Development Award (IDeA) from the National Institute of General Medical Sciences of the National Institutes of Health under grant number P20 GM103423. The funding sources played no role in the design of the study, in collection, analysis, and interpretation of data, or in writing the manuscript.

\section{ACKNOWLEDGMENTS}

Biorender.com was used to create Figures 1, 2 and 4.

6. Moore JB, June CH. Cytokine Release Syndrome in Severe COVID-19. Science (2020) 368:473-4. doi: 10.1126/science.abb8925

7. Hussell T, Cavanagh MM. The Innate Immune Rheostat: Influence on Lung Inflammatory Disease and Secondary Bacterial Pneumonia. Biochem Soc Trans (2009) 37:811-3. doi: 10.1042/BST0370811

8. Gabor KA, Goody MF, Mowel WK, Breitbach ME, Gratacap RL, Witten PE, et al. Influenza A Virus Infection in Zebrafish Recapitulates Mammalian Infection and Sensitivity to Anti-Influenza Drug Treatment. Dis Model Mech (2014) 7:1227-37. doi: 10.1242/dmm.014746

9. Gore AV, Pillay LM, Venero Galanternik M, Weinstein BM. The Zebrafish: A Fintastic Model for Hematopoietic Development and Disease. Wiley Interdiscip Rev Dev Biol (2018) 7:e312. doi: 10.1002/wdev.312

10. Murayama E, Kissa K, Zapata A, Mordelet E, Briolat V, Lin HF, et al. Tracing Hematopoietic Precursor Migration to Successive Hematopoietic Organs During Zebrafish Development. Immunity (2006) 25:963-75. doi: 10.1016/ j.immuni.2006.10.015 
11. Avagyan S, Zon LI. Fish to Learn: Insights Into Blood Development and Blood Disorders From Zebrafish Hematopoiesis. Hum Gene Ther (2016) 27:287-94. doi: 10.1089/hum.2016.024

12. de Jong JL, Zon LI. Use of the Zebrafish System to Study Primitive and Definitive Hematopoiesis. Annu Rev Genet (2005) 39:481-501. doi: 10.1146/ annurev.genet.39.073003.095931

13. Henry KM, Loynes CA, Whyte MK, Renshaw SA. Zebrafish as a Model for the Study of Neutrophil Biology. J Leukoc Biol (2013) 94:633-42. doi: 10.1189/jlb.1112594

14. Detrich HW, Kieran MW, Chan FY, Barone LM, Yee K, Rundstadler JA, et al. Intraembryonic Hematopoietic Cell Migration During Vertebrate Development. Proc Natl Acad Sci USA (1995) 92:10713-7. doi: 10.1073/ pnas.92.23.10713

15. Haslett C. Granulocyte Apoptosis and its Role in the Resolution and Control of Lung Inflammation. Am J Respir Crit Care Med (1999) 160:S5-11. doi: 10.1164/ajrccm.160.supplement_1.4

16. Phennicie RT, Sullivan MJ, Singer JT, Yoder JA, Kim CH. Specific Resistance to Pseudomonas Aeruginosa Infection in Zebrafish is Mediated by the Cystic Fibrosis Transmembrane Conductance Regulator. Infect Immun (2010) 78:4542-50. doi: 10.1128/IAI.00302-10

17. Brothers KM, Gratacap RL, Barker SE, Newman ZR, Norum A, Wheeler RT. NADPH Oxidase-Driven Phagocyte Recruitment Controls Candida Albicans Filamentous Growth and Prevents Mortality. PloS Pathog (2013) 9:e1003634. doi: 10.1371/journal.ppat.1003634

18. Brothers KM, Newman ZR, Wheeler RT. Live Imaging of Disseminated Candidiasis in Zebrafish Reveals Role of Phagocyte Oxidase in Limiting Filamentous Growth. Eukaryot Cell (2011) 10:932-44. doi: 10.1128/ EC.05005-11

19. Davis JM, Huang M, Botts MR, Hull CM, Huttenlocher A. A Zebrafish Model of Cryptococcal Infection Reveals Roles for Macrophages, Endothelial Cells, and Neutrophils in the Establishment and Control of Sustained Fungemia. Infect Immun (2016) 84:3047-62. doi: 10.1128/IAI.00506-16

20. Feng J, Chen Z, He L, Xiao X, Chen C, Chu J, et al. Acud Gene Knockout Attenuates the Virulence of Talaromyces Marneffei in a Zebrafish Model. Mycobiology (2019) 47:207-16. doi: 10.1080/12298093.2019.1620975

21. Knox BP, Deng Q, Rood M, Eickhoff JC, Keller NP, Huttenlocher A. Distinct Innate Immune Phagocyte Responses to Aspergillus Fumigatus Conidia and Hyphae in Zebrafish Larvae. Eukaryot Cell (2014) 13:1266-77. doi: 10.1128/ EC.00080-14

22. Voelz K, Gratacap RL, Wheeler RT. A Zebrafish Larval Model Reveals Early Tissue-Specific Innate Immune Responses to Mucor Circinelloides. Dis Model Mech (2015) 8:1375-88. doi: 10.1242/dmm.019992

23. Tenor JL, Oehlers SH, Yang JL, Tobin DM, Perfect JR. Live Imaging of HostParasite Interactions in a Zebrafish Infection Model Reveals Cryptococcal Determinants of Virulence and Central Nervous System Invasion. mBio (2015) 6:e01425-15. doi: 10.1128/mBio.01425-15

24. Sullivan C, Jurcyzszak D, Goody MF, Gabor KA, Longfellow JR, Millard PJ, et al. Using Zebrafish Models of Human Influenza A Virus Infections to Screen Antiviral Drugs and Characterize Host Immune Cell Responses. J Vis $\operatorname{Exp}$ (2017) 119:552357. doi: 10.3791/55235

25. Goody M, Jurczyszak D, Kim C, Henry C. Influenza A Virus Infection Damages Zebrafish Skeletal Muscle and Exacerbates Disease in Zebrafish Modeling Duchenne Muscular Dystrophy. PloS Curr (2017) 1. doi: 10.1371/ currents.md.8a7e35c50fa2b48156799d3c39788175

26. Niethammer P, Grabher C, Look AT, Mitchison TJ. A Tissue-Scale Gradient of Hydrogen Peroxide Mediates Rapid Wound Detection in Zebrafish. Nature (2009) 459:996-9. doi: 10.1038/nature08119

27. Lieschke GJ, Oates AC, Crowhurst MO, Ward AC, Layton JE. Morphologic and Functional Characterization of Granulocytes and Macrophages in Embryonic and Adult Zebrafish. Blood (2001) 98:3087-96. doi: 10.1182/blood.V98.10.3087

28. Bennett CM, Kanki JP, Rhodes J, Liu TX, Paw BH, Kieran MW, et al. Myelopoiesis in the Zebrafish, Danio Rerio. Blood (2001) 98:643-51. doi: 10.1182/blood.V98.3.643

29. Chapman AL, Skaff O, Senthilmohan R, Kettle AJ, Davies MJ. Hypobromous Acid and Bromamine Production by Neutrophils and Modulation by Superoxide. Biochem J (2009) 417:773-81. doi: 10.1042/BJ20071563

30. Urban CF, Ermert D, Schmid M, Abu-Abed U, Goosmann C, Nacken W, et al. Neutrophil Extracellular Traps Contain Calprotectin, a Cytosolic
Protein Complex Involved in Host Defense Against Candida Albicans. PloS Pathog (2009) 5:e1000639. doi: 10.1371/journal.ppat.1000639

31. Palic D, Andreasen CB, Ostojic J, Tell RM, Roth JA. Zebrafish (Danio Rerio) Whole Kidney Assays to Measure Neutrophil Extracellular Trap Release and Degranulation of Primary Granules. J Immunol Methods (2007) 319:87-97. doi: 10.1016/j.jim.2006.11.003

32. Gratacap RL, Scherer AK, Seman BG, Wheeler RT. Control of Mucosal Candidiasis in the Zebrafish Swim Bladder Depends on Neutrophils That Block Filament Invasion and Drive Extracellular-Trap Production. Infect Immun (2017) 85(9):e00276-17. doi: 10.1128/IAI.00276-17

33. Johnson CJ, Davis JM, Huttenlocher A, Kernien JF, Nett JE. Emerging Fungal Pathogen Candida Auris Evades Neutrophil Attack. mBio (2018) 9 (4):e01403-18. doi: 10.1128/mBio.01403-18

34. Papayannopoulos V, Metzler KD, Hakkim A, Zychlinsky A. Neutrophil Elastase and Myeloperoxidase Regulate the Formation of Neutrophil Extracellular Traps. J Cell Biol (2010) 191:677-91. doi: 10.1083/jcb.201006052

35. Jing CB, Chen Y, Dong M, Peng XL, Jia XE, Gao L, et al. Phospholipase C Gamma-1 is Required for Granulocyte Maturation in Zebrafish. Dev Biol (2013) 374:24-31. doi: 10.1016/j.ydbio.2012.11.032

36. Renshaw SA, Loynes CA, Trushell DM, Elworthy S, Ingham PW, Whyte MK. A Transgenic Zebrafish Model of Neutrophilic Inflammation. Blood (2006) 108:3976-8. doi: 10.1182/blood-2006-05-024075

37. Mathias JR, Perrin BJ, Liu TX, Kanki J, Look AT, Huttenlocher A. Resolution of Inflammation by Retrograde Chemotaxis of Neutrophils in Transgenic Zebrafish. J Leukoc Biol (2006) 80:1281-8. doi: 10.1189/jlb.0506346

38. Hall C, Flores MV, Storm T, Crosier K, Crosier P. The Zebrafish Lysozyme C Promoter Drives Myeloid-Specific Expression in Transgenic Fish. BMC Dev Biol (2007) 7:42. doi: 10.1186/1471-213X-7-42

39. Yoo SK, Deng Q, Cavnar PJ, Wu YI, Hahn KM, Huttenlocher A. Differential Regulation of Protrusion and Polarity by PI3K During Neutrophil Motility in Live Zebrafish. Dev Cell (2010) 18:226-36. doi: 10.1016/ j.devcel.2009.11.015

40. Gurskaya NG, Verkhusha VV, Shcheglov AS, Staroverov DB, Chepurnykh TV, Fradkov AF, et al. Engineering of a Monomeric Green-to-Red Photoactivatable Fluorescent Protein Induced by Blue Light. Nat Biotechnol (2006) 24:461-5. doi: 10.1038/nbt1191

41. Yoo SK, Huttenlocher A. Spatiotemporal Photolabeling of Neutrophil Trafficking During Inflammation in Live Zebrafish. J Leukoc Biol (2011) 89:661-7. doi: 10.1189/jlb.1010567

42. Ellett F, Pase L, Hayman JW, Andrianopoulos A, Lieschke GJ. Mpeg1 Promoter Transgenes Direct Macrophage-Lineage Expression in Zebrafish. Blood (2011) 117:e49-56. doi: 10.1182/blood-2010-10-314120

43. Zakrzewska A, Cui C, Stockhammer OW, Benard EL, Spaink HP, Meijer AH. Macrophage-Specific Gene Functions in Spil-directed Innate Immunity. Blood (2010) 116:e1-11. doi: 10.1182/blood-2010-01-262873

44. Roca FJ, Ramakrishnan L. TNF Dually Mediates Resistance and Susceptibility to Mycobacteria Via Mitochondrial Reactive Oxygen Species. Cell (2013) 153:521-34. doi: 10.1016/j.cell.2013.03.022

45. Harvie EA, Green JM, Neely MN, Huttenlocher A. Innate Immune Response to Streptococcus Iniae Infection in Zebrafish Larvae. Infect Immun (2013) 81:110-21. doi: 10.1128/IAI.00642-12

46. Walton EM, Cronan MR, Beerman RW, Tobin DM. The MacrophageSpecific Promoter Mfap4 Allows Live, Long-Term Analysis of Macrophage Behavior During Mycobacterial Infection in Zebrafish. PloS One (2015) 10: e0138949. doi: 10.1371/journal.pone.0138949

47. Benard EL, Racz PI, Rougeot J, Nezhinsky AE, Verbeek FJ, Spaink HP, et al. Macrophage-Expressed Perforins Mpeg1 and mpeg1.2 Have an AntiBacterial Function in Zebrafish. J Innate Immun (2015) 7:136-52. doi: $10.1159 / 000366103$

48. King BL, Rosenstein MC, Smith AM, Dykeman CA, Smith GA, Yin VP. RegenDbase: A Comparative Database of Noncoding RNA Regulation of Tissue Regeneration Circuits Across Multiple Taxa. NPJ Regener Med (2018) 3:10. doi: 10.1038/s41536-018-0049-0

49. Fan HB, Liu YJ, Wang L, Du TT, Dong M, Gao L, et al. miR-142-3p Acts as an Essential Modulator of Neutrophil Development in Zebrafish. Blood (2014) 124:1320-30. doi: 10.1182/blood-2013-12-545012

50. Zhang S, Cui P. Complement System in Zebrafish. Dev Comp Immunol (2014) 46:3-10. doi: 10.1016/j.dci.2014.01.010 
51. Varela M, Romero A, Dios S, van der Vaart M, Figueras A, Meijer AH, et al. Cellular Visualization of Macrophage Pyroptosis and interleukin-1beta Release in a Viral Hemorrhagic Infection in Zebrafish Larvae. $J$ Virol (2014) 88:12026-40. doi: 10.1128/JVI.02056-14

52. Liu X, Cai X, Zhang D, Xu C, Xiao W. Zebrafish Foxo3b Negatively Regulates Antiviral Response Through Suppressing the Transactivity of Irf3 and Irf7. J Immunol (2016) 197:4736-49. doi: 10.4049/ jimmunol.1601187

53. Rakus K, Mojzesz M, Widziolek M, Pooranachandran N, Teitge F, Surachetpong W, et al. Antiviral Response of Adult Zebrafish (Danio Rerio) During Tilapia Lake Virus (TiLV) Infection. Fish Shellfish Immunol (2020) 101:1-8. doi: 10.1016/j.fsi.2020.03.040

54. Garcia-Valtanen P, Martinez-Lopez A, Ortega-Villaizan M, Perez L, Coll JM, Estepa A. In Addition to its Antiviral and Immunomodulatory Properties, the Zebrafish Beta-Defensin 2 (zfBD2) is a Potent Viral DNA Vaccine Molecular Adjuvant. Antiviral Res (2014) 101:136-47. doi: 10.1016/ j.antiviral.2013.11.009

55. Espin-Palazon R, Martinez-Lopez A, Roca FJ, Lopez-Munoz A, Tyrkalska SD, Candel S, et al. Tnfalpha Impairs Rhabdoviral Clearance by Inhibiting the Host Autophagic Antiviral Response. PloS Pathog (2016) 12:e1005699. doi: 10.1371/journal.ppat.1005699

56. Zhu J, Liu X, Cai X, Ouyang G, Zha H, Zhou Z, et al. Zebrafish Prmt3 Negatively Regulates Antiviral Responses. FASEB J (2020) 34:10212-27. doi: 10.1096/fj.201902569R

57. Levraud J-P, Boudinot P, Colin I, Benmansour A, Peyrieras N, Herbomel P, et al. Identification of the Zebrafish Ifn Receptor: Implications for the Origin of the Vertebrate Ifn System. J Immunol (2007) 178:4385-94. doi: 10.4049/ jimmunol.178.7.4385

58. Altmann SM, Mellon MT, Distel DL, Kim CH. Molecular and Functional Analysis of an Interferon Gene From the Zebrafish, Danio Rerio. J Virol (2003) 77:1992-2002. doi: 10.1128/JVI.77.3.1992-2002.2003

59. Phelan PE, Pressley ME, Witten PE, Mellon MT, Blake S, Kim CH. Characterization of Snakehead Rhabdovirus Infection in Zebrafish (Danio Rerio). J Virol (2005) 79:1842-52. doi: 10.1128/JVI.79.3.1842-1852.2005

60. Gabor KA, Charette JR, Pietraszewski MJ, Wingfield DJ, Shim JS, Millard PJ, et al. A DN-mda5 Transgenic Zebrafish Model Demonstrates That Mda5 Plays an Important Role in Snakehead Rhabdovirus Resistance. Dev Comp Immunol (2015) 51:298-304. doi: 10.1016/j.dci.2015.01.006

61. Langevin C, Van derAa LM, Houel A, Torhy C, Briolat V, Lunazzi A, et al. Zebrafish ISG15 Exerts a Strong Antiviral Activity Against RNA and DNA Viruses and Regulates the Interferon Response. J Virol (2013) 87:10025-36. doi: 10.1128/JVI.01294-12

62. Feng H, Zhang YB, Zhang QM, Li Z, Zhang QY, Gui JF. Zebrafish IRF1 Regulates IFN Antiviral Response Through Binding to IFNvarphil and IFNvarphi3 Promoters Downstream of MyD88 Signaling. J Immunol (2015) 194:1225-38. doi: 10.4049/jimmunol.1402415

63. Zou PF, Chang MX, Li Y, Xue NN, Li JH, Chen SN, et al. NOD2 in Zebrafish Functions in Antibacterial and Also Antiviral Responses Via NF-kappaB, and Also MDA5, RIG-I and MAVS. Fish Shellfish Immunol (2016) 55:17385. doi: 10.1016/j.fsi.2016.05.031

64. Ouyang G, Liao Q, Zhang D, Rong F, Cai X, Fan S, et al. Zebrafish NFkappaB/p65 is Required for Antiviral Responses. J Immunol (2020) 204:3019-29. doi: 10.4049/jimmunol.1900309

65. Phelan PE, Mellon MT, Kim CH. Functional Characterization of Full-Length TLR3, Irak-4, and TRAF6 in Zebrafish (Danio Rerio). Mol Immunol (2005) 42:1057-71. doi: 10.1016/j.molimm.2004.11.005

66. Willett CE, Cortes A, Zuasti A, Zapata AG. Early Hematopoiesis and Developing Lymphoid Organs in the Zebrafish. Dev Dyn (1999) 214:323-36. doi: 10.1002/(SICI) 1097-0177(199904)214:4<323::AID-AJA5>3.0.CO;2-3

67. Scaffidi P, Misteli T, Bianchi ME. Release of Chromatin Protein HMGB1 by Necrotic Cells Triggers Inflammation. Nature (2002) 418:191-5. doi: $10.1038 /$ nature00858

68. Lee BL, Moon JE, Shu JH, Yuan L, Newman ZR, Schekman R, et al. UNC93B1 Mediates Differential Trafficking of Endosomal Tlrs. Elife (2013) 2:e00291. doi: 10.7554/eLife.00291

69. Greulich W, Wagner M, Gaidt MM, Stafford C, Cheng Y, Linder A, et al. Tlr8 Is a Sensor of RNase T2 Degradation Products. Cell (2019) 179:126475.e13. doi: 10.1016/j.cell.2019.11.001
70. Meijer AH, Gabby Krens SF, Medina Rodriguez IA, He S, Bitter W, Ewa Snaar-Jagalska B, et al. Expression Analysis of the Toll-like Receptor and TIR Domain Adaptor Families of Zebrafish. Mol Immunol (2004) 40:773-83. doi: 10.1016/j.molimm.2003.10.003

71. Yeh DW, Liu YL, Lo YC, Yuh CH, Yu GY, Lo JF, et al. Toll-Like Receptor 9 and 21 Have Different Ligand Recognition Profiles and Cooperatively Mediate Activity of CpG-oligodeoxynucleotides in Zebrafish. Proc Natl Acad Sci USA (2013) 110:20711-6. doi: 10.1073/pnas.1305273110

72. Yang S, Marin-Juez R, Meijer AH, Spaink HP. Common and Specific Downstream Signaling Targets Controlled by Tlr2 and Tlr5 Innate Immune Signaling in Zebrafish. BMC Genomics (2015) 16:547. doi: 10.1186/s12864-015-1740-9

73. Sahoo BR, Dikhit MR, Bhoi GK, Maharana J, Lenka SK, Dubey PK, et al. Understanding the Distinguishable Structural and Functional Features in Zebrafish TLR3 and TLR22, and Their Binding Modes With Fish dsRNA Viruses: An Exploratory Structural Model Analysis. Amino Acids (2015) 47:381-400. doi: 10.1007/s00726-014-1872-2

74. Sullivan C, Postlethwait JH, Lage CR, Millard PJ, Kim CH. Evidence for Evolving Toll-IL-1 Receptor-Containing Adaptor Molecule Function in Vertebrates. J Immunol (2007) 178:4517-27. doi: 10.4049/ jimmunol.178.7.4517

75. Sullivan C, Charette J, Catchen J, Lage CR, Giasson G, Postlethwait JH, et al. The Gene History of Zebrafish tlr4a and tlr4b is Predictive of Their Divergent Functions. J Immunol (2009) 183:5896-908. doi: 10.4049/ jimmunol.0803285

76. Voogdt CGP, Wagenaar JA, van Putten JPM. Duplicated TLR5 of Zebrafish Functions as a Heterodimeric Receptor. Proc Natl Acad Sci USA (2018) 115: E3221-9. doi: 10.1073/pnas.1719245115

77. Yoon SI, Kurnasov O, Natarajan V, Hong M, Gudkov AV, Osterman AL, et al. Structural Basis of TLR5-flagellin Recognition and Signaling. Science (2012) 335:859-64. doi: 10.1126/science.1215584

78. Muire PJ, Hanson LA, Wills R, Petrie-Hanson L. Differential Gene Expression Following TLR Stimulation in rag1-/- Mutant Zebrafish Tissues and Morphological Descriptions of Lymphocyte-Like Cell Populations. PloS One (2017) 12:e0184077. doi: 10.1371/ journal.pone. 0184077

79. Matsuo A, Oshiumi H, Tsujita T, Mitani H, Kasai H, Yoshimizu M, et al. Teleost TLR22 Recognizes RNA Duplex to Induce IFN and Protect Cells From Birnaviruses. J Immunol (2008) 181:3474-85. doi: 10.4049/ jimmunol.181.5.3474

80. Fitzgerald KA, Kagan JC. Toll-Like Receptors and the Control of Immunity. Cell (2020) 180:1044-66. doi: 10.1016/j.cell.2020.02.041

81. Candel S, Sepulcre MP, Espin-Palazon R, Tyrkalska SD, de Oliveira S, Meseguer J, et al. Md1 and Rp105 Regulate Innate Immunity and Viral Resistance in Zebrafish. Dev Comp Immunol (2015) 50:155-65. doi: 10.1016/ j.dci.2015.01.005

82. Howe KL, Achuthan P, Allen J, Allen J, Alvarez-Jarreta J, Amode MR, et al. Ensembl 2021. Nucleic Acids Res (2021) 49:D884-91. doi: 10.1093/nar/ gkaa942

83. Howe DG, Ramachandran S, Bradford YM, Fashena D, Toro S, Eagle A, et al. The Zebrafish Information Network: Major Gene Page and Home Page Updates. Nucleic Acids Res (2021) 49:D1058-64. doi: 10.1093/nar/gkaa1010

84. Catchen JM, Conery JS, Postlethwait JH. Automated Identification of Conserved Synteny After Whole-Genome Duplication. Genome Res (2009) 19:1497-505. doi: 10.1101/gr.090480.108

85. Braasch I, Gehrke AR, Smith JJ, Kawasaki K, Manousaki T, Pasquier J, et al. The Spotted Gar Genome Illuminates Vertebrate Evolution and Facilitates Human-Teleost Comparisons. Nat Genet (2016) 48:427-37. doi: 10.1038/ ng. 3526

86. Mathur A, Hayward JA, Man SM. Molecular Mechanisms of Inflammasome Signaling. J Leukoc Biol (2018) 103:233-57. doi: 10.1189/jlb.3MR0617-250R

87. Li JY, Wang YY, Shao T, Fan DD, Lin AF, Xiang LX, et al. The Zebrafish NLRP3 Inflammasome has Functional Roles in ASC-dependent interleukinlbeta Maturation and Gasdermin E-mediated Pyroptosis. J Biol Chem (2020) 295:1120-41. doi: 10.1016/S0021-9258(17)49920-0

88. Howe K, Schiffer PH, Zielinski J, Wiehe T, Laird GK, Marioni JC, et al. Structure and Evolutionary History of a Large Family of NLR Proteins in the Zebrafish. Open Biol (2016) 6:160009. doi: 10.1098/rsob.160009 
89. Li JY, Gao K, Shao T, Fan DD, Hu CB, Sun CC, et al. Characterization of an NLRP1 Inflammasome From Zebrafish Reveals a Unique Sequential Activation Mechanism Underlying Inflammatory Caspases in Ancient Vertebrates. J Immunol (2018) 201:1946-66. doi: 10.4049/jimmunol.1800498

90. Li Y, Huang Y, Cao X, Yin X, Jin X, Liu S, et al. Functional and Structural Characterization of Zebrafish ASC. FEBS J (2018) 285:2691-707. doi: $10.1111 /$ febs. 14514

91. Tyrkalska SD, Candel S, Perez-Oliva AB, Valera A, Alcaraz-Perez F, GarciaMoreno D, et al. Identification of an Evolutionarily Conserved Ankyrin Domain-Containing Protein, Caiap, Which Regulates InflammasomeDependent Resistance to Bacterial Infection. Front Immunol (2017) 8:1375. doi: 10.3389/fimmu.2017.01375

92. Huising MO, Stet RJ, Savelkoul HF, Verburg-van Kemenade BM. The Molecular Evolution of the Interleukin-1 Family of Cytokines; IL-18 in Teleost Fish. Dev Comp Immunol (2004) 28:395-413. doi: 10.1016/ j.dci.2003.09.005

93. Zou J, Bird S, Truckle J, Bols N, Horne M, Secombes C. Identification and Expression Analysis of an IL-18 Homologue and its Alternatively Spliced Form in Rainbow Trout (Oncorhynchus Mykiss). Eur J Biochem (2004) 271:1913-23. doi: 10.1111/j.1432-1033.2004.04101.x

94. Palha N, Guivel-Benhassine F, Briolat V, Lutfalla G, Sourisseau M, Ellett F, et al. Real-Time Whole-Body Visualization of Chikungunya Virus Infection and Host Interferon Response in Zebrafish. PloS Pathog (2013) 9:e1003619. doi: 10.1371/journal.ppat.1003619

95. Benard EL, Roobol SJ, Spaink HP, Meijer AH. Phagocytosis of Mycobacteria by Zebrafish Macrophages is Dependent on the Scavenger Receptor Marco, a Key Control Factor of Pro-Inflammatory Signalling. Dev Comp Immunol (2014) 47:223-33. doi: 10.1016/j.dci.2014.07.022

96. Encinas P, Rodriguez-Milla MA, Novoa B, Estepa A, Figueras A, Coll J. Zebrafish Fin Immune Responses During High Mortality Infections With Viral Haemorrhagic Septicemia Rhabdovirus. A Proteomic and Transcriptomic Approach. BMC Genomics (2010) 11:518. doi: 10.1186/1471-2164-11-518

97. Fink IR, Benard EL, Hermsen T, Meijer AH, Forlenza M, Wiegertjes GF. Molecular and Functional Characterization of the Scavenger Receptor CD36 in Zebrafish and Common Carp. Mol Immunol (2015) 63:381-93. doi: 10.1016/j.molimm.2014.09.010

98. Kawasaki N, Kawasaki T, Yamashina I. Isolation and Characterization of a Mannan-Binding Protein From Human Serum. J Biochem (1983) 94:937-47. doi: 10.1093/oxfordjournals.jbchem.a134437

99. Malhotra R, Haurum JS, Thiel S, Sim RB. Binding of Human Collectins (SPa and MBP) to Influenza Virus. Biochem J (1994) 304(Pt 2):455-61. doi: 10.1042/bj3040455

100. Londrigan SL, Turville SG, Tate MD, Deng YM, Brooks AG, Reading PC. NLinked Glycosylation Facilitates Sialic Acid-Independent Attachment and Entry of Influenza A Viruses Into Cells Expressing DC-SIGN or L-SIGN. J Virol (2011) 85:2990-3000. doi: 10.1128/JVI.01705-10

101. Coulthard LG, Woodruff TM. Is the Complement Activation Product C3a a Proinflammatory Molecule? Re-evaluating the Evidence and the Myth. J Immunol (2015) 194:3542-8. doi: 10.4049/jimmunol.1403068

102. Wu MC, Brennan FH, Lynch JP, Mantovani S, Phipps S, Wetsel RA, et al. The Receptor for Complement Component C3a Mediates Protection From Intestinal Ischemia-Reperfusion Injuries by Inhibiting Neutrophil Mobilization. Proc Natl Acad Sci USA (2013) 110:9439-44. doi: 10.1073/ pnas. 1218815110

103. Xu DZ, Zaets SB, Chen R, Lu Q, Rajan H, Yang X, et al. Elimination of C5aR Prevents Intestinal Mucosal Damage and Attenuates Neutrophil Infiltration in Local and Remote Organs. Shock (2009) 31:493-9. doi: 10.1097/ SHK.0b013e318188b3cc

104. Bello-Perez M, Falco A, Medina-Gali R, Pereiro P, Encinar JA, Novoa B, et al. Neutralization of Viral Infectivity by Zebrafish C-Reactive Protein Isoforms. Mol Immunol (2017) 91:145-55. doi: 10.1016/j.molimm.2017.09.005

105. Muller U, Steinhoff U, Reis LF, Hemmi S, Pavlovic J, Zinkernagel RM, et al. Functional Role of Type I and Type II Interferons in Antiviral Defense. Science (1994) 264:1918-21. doi: 10.1126/science.8009221

106. Igawa D, Sakai M, Savan R. An Unexpected Discovery of Two Interferon Gamma-Like Genes Along With Interleukin (IL)-22 and -26 From Teleost: IL-22 and -26 Genes Have Been Described for the First Time Outside Mammals. Mol Immunol (2006) 43:999-1009. doi: 10.1016/j.molimm.2005.05.009
107. Zou J, Tafalla C, Truckle J, Secombes CJ. Identification of a Second Group of Type I Ifns in Fish Sheds Light on IFN Evolution in Vertebrates. J Immunol (2007) 179:3859-71. doi: 10.4049/jimmunol.179.6.3859

108. Aggad D, Mazel M, Boudinot P, Mogensen KE, Hamming OJ, Hartmann R, et al. The Two Groups of Zebrafish Virus-Induced Interferons Signal Via Distinct Receptors With Specific and Shared Chains. J Immunol (2009) 183:3924-31. doi: 10.4049/jimmunol.0901495

109. Alvarez-Rodriguez M, Pereiro P, Reyes-Lopez FE, Tort L, Figueras A, Novoa B. Analysis of the Long-Lived Responses Induced by Immunostimulants and Their Effects on a Viral Infection in Zebrafish (Danio Rerio). Front Immunol (2018) 9:1575. doi: 10.3389/fimmu.2018.01575

110. Langevin C, Boudinot P, Collet B. Ifn Signaling in Inflammation and Viral Infections: New Insights From Fish Models. Viruses (2019) 11(3):302. doi: 10.3390/v11030302

111. Boudinot P, Langevin C, Secombes CJ, Levraud JP. The Peculiar Characteristics of Fish Type I Interferons. Viruses (2016) 8(11):298. doi: 10.3390/v8110298

112. Langevin C, Aleksejeva E, Passoni G, Palha N, Levraud JP, Boudinot P. The Antiviral Innate Immune Response in Fish: Evolution and Conservation of the IFN System. J Mol Biol (2013) 425:4904-20. doi: 10.1016/j.jmb.2013.09.033

113. Hamming OJ, Lutfalla G, Levraud JP, Hartmann R. Crystal Structure of Zebrafish Interferons I and II Reveals Conservation of Type I Interferon Structure in Vertebrates. J Virol (2011) 85:8181-7. doi: 10.1128/JVI.00521-11

114. Gabor KA, Stevens CR, Pietraszewski MJ, Gould TJ, Shim J, Yoder JA, et al. Super Resolution Microscopy Reveals That Caveolin-1 is Required for Spatial Organization of CRFB1 and Subsequent Antiviral Signaling in Zebrafish. PloS One (2013) 8:e68759. doi: 10.1371/journal.pone.0068759

115. Schoggins JW, Wilson SJ, Panis M, Murphy MY, Jones CT, Bieniasz P, et al. A Diverse Range of Gene Products are Effectors of the Type I Interferon Antiviral Response. Nature (2011) 472:481-5. doi: 10.1038/nature09907

116. Altmann SM, Mellon MT, Johnson MC, Paw BH, Trede NS, Zon LI, et al. Cloning and Characterization of an $\mathrm{Mx}$ Gene and its Corresponding Promoter From the Zebrafish, Danio Rerio. Dev Comp Immunol (2004) 28:295-306. doi: 10.1016/j.dci.2003.09.001

117. Briolat V, Jouneau L, Carvalho R, Palha N, Langevin C, Herbomel P, et al. Contrasted Innate Responses to Two Viruses in Zebrafish: Insights Into the Ancestral Repertoire of Vertebrate IFN-stimulated Genes. J Immunol (2014) 192:4328-41. doi: 10.4049/jimmunol.1302611

118. Wang Y, Zhang H, Lu Y, Wang F, Liu L, Liu J, et al. Comparative Transcriptome Analysis of Zebrafish (Danio Rerio) Brain and Spleen Infected With Spring Viremia of Carp Virus (SVCV). Fish Shellfish Immunol (2017) 69:35-45. doi: 10.1016/j.fsi.2017.07.055

119. Kawahara T, Quinn MT, Lambeth JD. Molecular Evolution of the Reactive Oxygen-Generating NADPH Oxidase (Nox/Duox) Family of Enzymes. BMC Evol Biol (2007) 7:109. doi: 10.1186/1471-2148-7-109

120. Schoen TJ, Rosowski EE, Knox BP, Bennin D, Keller NP, Huttenlocher A. Neutrophil Phagocyte Oxidase Activity Controls Invasive Fungal Growth and Inflammation in Zebrafish. J Cell Sci (2019) 133(5):jcs236539. doi: $10.1242 /$ jcs. 236539

121. Hancock JT, Jones OT. The Inhibition by Diphenyleneiodonium and its Analogues of Superoxide Generation by Macrophages. Biochem J (1987) 242:103-7. doi: 10.1042/bj2420103

122. Bosco EE, Kumar S, Marchioni F, Biesiada J, Kordos M, Szczur K, et al. Rational Design of Small Molecule Inhibitors Targeting the Rac Gtpase-p67 (phox) Signaling Axis in Inflammation. Chem Biol (2012) 19:228-42. doi: 10.1016/j.chembiol.2011.12.017

123. ten Freyhaus H, Huntgeburth M, Wingler K, Schnitker J, Baumer AT, Vantler M, et al. Novel Nox Inhibitor VAS2870 Attenuates PDGFdependent Smooth Muscle Cell Chemotaxis, But Not Proliferation. Cardiovasc Res (2006) 71:331-41. doi: 10.1016/j.cardiores.2006.01.022

124. Efimova O, Szankasi P, Kelley TW. Ncf1 (p47phox) is Essential for Direct Regulatory T Cell Mediated Suppression of CD4+ Effector T Cells. PloS One (2011) 6:e16013. doi: 10.1371/journal.pone.0016013

125. Weaver CJ, Leung YF, Suter DM. Expression Dynamics of NADPH Oxidases During Early Zebrafish Development. J Comp Neurol (2016) 524:2130-41. doi: $10.1002 /$ cne. 23938

126. Rieger S, Sagasti A. Hydrogen Peroxide Promotes Injury-Induced Peripheral Sensory Axon Regeneration in the Zebrafish Skin. PloS Biol (2011) 9: e1000621. doi: 10.1371/journal.pbio.1000621 
127. Jaquet V, Marcoux J, Forest E, Leidal KG, McCormick S, Westermaier Y, et al. NADPH Oxidase (NOX) Isoforms are Inhibited by Celastrol With a Dual Mode of Action. Br J Pharmacol (2011) 164:507-20. doi: 10.1111/ j.1476-5381.2011.01439.x

128. Gianni D, Taulet N, Zhang H, DerMardirossian C, Kister J, Martinez L, et al. A Novel and Specific NADPH Oxidase-1 (Nox1) Small-Molecule Inhibitor Blocks the Formation of Functional Invadopodia in Human Colon Cancer Cells. ACS Chem Biol (2010) 5:981-93. doi: 10.1021/cb100219n

129. Gorin Y, Cavaglieri RC, Khazim K, Lee DY, Bruno F, Thakur S, et al. Targeting NADPH Oxidase With a Novel Dual Nox1/Nox4 Inhibitor Attenuates Renal Pathology in Type 1 Diabetes. Am J Physiol Renal Physiol (2015) 308:F1276-87. doi: 10.1152/ajprenal.00396.2014

130. Gaggini F, Laleu B, Orchard M, Fioraso-Cartier L, Cagnon L, HoungninouMolango S, et al. Design, Synthesis and Biological Activity of Original Pyrazolo-Pyrido-Diazepine, -Pyrazine and -Oxazine Dione Derivatives as Novel Dual Nox4/Nox1 Inhibitors. Bioorg Med Chem (2011) 19:6989-99. doi: 10.1016/j.bmc.2011.10.016

131. Wang X, Elksnis A, Wikstrom P, Walum E, Welsh N, Carlsson PO. The Novel NADPH Oxidase 4 Selective Inhibitor GLX7013114 Counteracts Human Islet Cell Death In Vitro. PloS One (2018) 13:e0204271. doi: 10.1371/journal.pone.0204271

132. Helfinger V, Palfi K, Weigert A, Schroder K. The NADPH Oxidase Nox4 Controls Macrophage Polarization in an NFkappaB-Dependent Manner. Oxid Med Cell Longev (2019) 2019:3264858. doi: 10.1155/2019/3264858

133. Kofler PA, Pircher H, von Grafenstein S, Diener T, Holl M, Liedl KR, et al. Characterisation of Nox4 Inhibitors From Edible Plants. Planta Med (2013) 79:244-52. doi: 10.1055/s-0032-1328129

134. Hermann AC, Millard PJ, Blake SL, Kim CH. Development of a Respiratory Burst Assay Using Zebrafish Kidneys and Embryos. J Immunol Methods (2004) 292:119-29. doi: 10.1016/j.jim.2004.06.016

135. Peterman EM, Sullivan C, Goody MF, Rodriguez-Nunez I, Yoder JA, Kim $\mathrm{CH}$. Neutralization of Mitochondrial Superoxide by Superoxide Dismutase 2 Promotes Bacterial Clearance and Regulates Phagocyte Numbers in Zebrafish. Infect Immun (2015) 83:430-40. doi: 10.1128/IAI.02245-14

136. Goody MF, Peterman E, Sullivan C, Kim CH. Quantification of the Respiratory Burst Response as an Indicator of Innate Immune Health in Zebrafish. J Vis Exp (2013) 79:50667. doi: 10.3791/50667

137. Nayak AS, Lage CR, Kim CH. Effects of Low Concentrations of Arsenic on the Innate Immune System of the Zebrafish (Danio Rerio). Toxicol Sci (2007) 98:118-24. doi: 10.1093/toxsci/kfm072

138. Mugoni V, Camporeale A, Santoro MM. Analysis of Oxidative Stress in Zebrafish Embryos. J Vis Exp (2014) 89:51328. doi: 10.3791/51328

139. Bernut A, Loynes CA, Floto RA, Renshaw SA. Deletion of Cftr Leads to an Excessive Neutrophilic Response and Defective Tissue Repair in a Zebrafish Model of Sterile Inflammation. Front Immunol (2020) 11:1733. doi: 10.3389/ fimmu.2020.01733

140. Loynes CA, Martin JS, Robertson A, Trushell DM, Ingham PW, Whyte MK, et al. Pivotal Advance: Pharmacological Manipulation of Inflammation Resolution During Spontaneously Resolving Tissue Neutrophilia in the Zebrafish. J Leukoc Biol (2010) 87:203-12. doi: 10.1189/jlb.0409255

141. Morash MG, Douglas SE, Robotham A, Ridley CM, Gallant JW, Soanes KH. The Zebrafish Embryo as a Tool for Screening and Characterizing Pleurocidin Host-Defense Peptides as Anti-Cancer Agents. Dis Model Mech (2011) 4:622-33. doi: 10.1242/dmm.007310

142. Ogrunc M, Di Micco R, Liontos M, Bombardelli L, Mione M, Fumagalli M, et al. Oncogene-Induced Reactive Oxygen Species Fuel Hyperproliferation and DNA Damage Response Activation. Cell Death Differ (2014) 21:9981012. doi: $10.1038 / \mathrm{cdd} .2014 .16$

143. Zhao H, Kalivendi S, Zhang H, Joseph J, Nithipatikom K, Vasquez-Vivar J, et al. Superoxide Reacts With Hydroethidine But Forms a Fluorescent Product That is Distinctly Different From Ethidium: Potential Implications in Intracellular Fluorescence Detection of Superoxide. Free Radic Biol Med (2003) 34:1359-68. doi: 10.1016/S0891-5849(03)00142-4

144. Phan QT, Sipka T, Gonzalez C, Levraud JP, Lutfalla G, Nguyen-Chi M. Neutrophils Use Superoxide to Control Bacterial Infection At a Distance. PloS Pathog (2018) 14:e1007157. doi: 10.1371/journal.ppat.1007157

145. Pase L, Layton JE, Wittmann C, Ellett F, Nowell CJ, Reyes-Aldasoro CC, et al. Neutrophil-Delivered Myeloperoxidase Dampens the Hydrogen Peroxide
Burst After Tissue Wounding in Zebrafish. Curr Biol (2012) 22:1818-24. doi: 10.1016/j.cub.2012.07.060

146. Walters KB, Green JM, Surfus JC, Yoo SK, Huttenlocher A. Live Imaging of Neutrophil Motility in a Zebrafish Model of WHIM Syndrome. Blood (2010) 116:2803-11. doi: 10.1182/blood-2010-03-276972

147. Deng Q, Yoo SK, Cavnar PJ, Green JM, Huttenlocher A. Dual Roles for Rac2 in Neutrophil Motility and Active Retention in Zebrafish Hematopoietic Tissue. Dev Cell (2011) 21:735-45. doi: 10.1016/j.devcel.2011.07.013

148. Hsu AY, Liu S, Syahirah R, Brasseale KA, Wan J, Deng Q. Inducible Overexpression of Zebrafish microRNA-722 Suppresses Chemotaxis of Human Neutrophil Like Cells. Mol Immunol (2019) 112:206-14. doi: 10.1016/j.molimm.2019.06.001

149. Hsu AY, Wang D, Gurol T, Zhou W, Zhu X, Lu HY, et al. Overexpression of microRNA-722 Fine-Tunes Neutrophilic Inflammation by Inhibiting Rac2 in Zebrafish. Dis Model Mech (2017) 10:1323-32. doi: 10.1242/dmm.030791

150. Hsu AY, Wang D, Liu S, Lu J, Syahirah R, Bennin DA, et al. Phenotypical microRNA Screen Reveals a Noncanonical Role of CDK2 in Regulating Neutrophil Migration. Proc Natl Acad Sci USA (2019) 116:18561-70. doi: 10.1073/pnas.1905221116

151. Elks PM, van der Vaart M, van Hensbergen V, Schutz E, Redd MJ, Murayama E, et al. Mycobacteria Counteract a TLR-mediated Nitrosative Defense Mechanism in a Zebrafish Infection Model. PloS One (2014) 9: e100928. doi: 10.1371/journal.pone.0100928

152. Liongue C, Hall CJ, O'Connell BA, Crosier P, Ward AC. Zebrafish Granulocyte Colony-Stimulating Factor Receptor Signaling Promotes Myelopoiesis and Myeloid Cell Migration. Blood (2009) 113:2535-46. doi: 10.1182/blood-2008-07-171967

153. Cazorla-Vazquez S, Steingruber M, Marschall M, Engel FB. Human Cytomegaloviral Multifunctional Protein Kinase pUL97 Impairs Zebrafish Embryonic Development and Increases Mortality. Sci Rep (2019) 9:7219. doi: 10.1038/s41598-019-43649-x

154. Meraner XE,P, Lu P, Perreira JM, Aker AM, McDougall WM, Zhuge R, et al. OR14I1 is a Receptor for the Human Cytomegalovirus Pentameric Complex and Defines Viral Epithelial Cell Tropism. Proc Natl Acad Sci USA (2019) 116:7043-52. doi: 10.1073/pnas.1814850116

155. Burgos JS, Ripoll-Gomez J, Alfaro JM, Sastre I, Valdivieso F. Zebrafish as a New Model for Herpes Simplex Virus Type 1 Infection. Zebrafish (2008) 5:323-33. doi: 10.1089/zeb.2008.0552

156. Antoine TE, Yakoub A, Maus E, Shukla D, Tiwari V. Zebrafish 3-Osulfotransferase-4 Generated Heparan Sulfate Mediates HSV-1 Entry and Spread. PloS One (2014) 9:e87302. doi: 10.1371/journal.pone.0087302

157. Ge R, Zhou Y, Peng R, Wang R, Li M, Zhang Y, et al. Conservation of the STING-Mediated Cytosolic DNA Sensing Pathway in Zebrafish. J Virol (2015) 89:7696-706. doi: 10.1128/JVI.01049-15

158. Antoine TE, Jones KS, Dale RM, Shukla D, Tiwari V. Zebrafish: Modeling for Herpes Simplex Virus Infections. Zebrafish (2014) 11:17-25. doi: 10.1089/ zeb.2013.0920

159. Zou M, De Koninck P, Neve RL, Friedrich RW. Fast Gene Transfer Into the Adult Zebrafish Brain by Herpes Simplex Virus 1 (HSV-1) and Electroporation: Methods and Optogenetic Applications. Front Neural Circuits (2014) 8:41. doi: 10.3389/fncir.2014.00041

160. Pringle ES, Wertman J, Melong N, Coombs AJ, Young AL, O'Leary D, et al. The Zebrafish Xenograft Platform-A Novel Tool for Modeling KshvAssociated Diseases. Viruses (2019) 12(1):12. doi: 10.20944/ preprints201911.0081.v1

161. Martin V, Mavian C, Lopez Bueno A, de Molina A, Diaz E, Andres G, et al. Establishment of a Zebrafish Infection Model for the Study of Wild-Type and Recombinant European Sheatfish Virus. J Virol (2015) 89:10702-6. doi: 10.1128/JVI.01580-15

162. Bermudez R, Losada AP, de Azevedo AM, Guerra-Varela J, Perez-Fernandez D, Sanchez L, et al. First Description of a Natural Infection With Spleen and Kidney Necrosis Virus in Zebrafish. J Fish Dis (2018) 41:1283-94. doi: $10.1111 /$ jfd. 12822

163. Xu X, Zhang L, Weng S, Huang Z, Lu J, Lan D, et al. A Zebrafish (Danio Rerio) Model of Infectious Spleen and Kidney Necrosis Virus (ISKNV) Infection. Virology (2008) 376:1-12. doi: 10.1016/j.virol.2007.12.026

164. Xiong XP, Dong CF, Xu X, Weng SP, Liu ZY, He JG. Proteomic Analysis of Zebrafish (Danio Rerio) Infected With Infectious Spleen and Kidney 
Necrosis Virus. Dev Comp Immunol (2011) 35:431-40. doi: 10.1016/ j.dci.2010.11.006

165. Sun C, Hu L, Liu S, Hu G, Zhang S. Antiviral Activity of Phosvitin From Zebrafish Danio Rerio. Dev Comp Immunol (2013) 40:28-34. doi: 10.1016/ j.dci.2012.12.009

166. LaPatra SE, Barone L, Jones GR, Zon LI. Effects of Infectious Hematopoietic Necrosis Virus and Infectious Pancreatic Necrosis Virus Infection on Hematopoietic Precursors of the Zebrafish. Blood Cells Mol Dis (2000) 26:445-52. doi: 10.1006/bcmd.2000.0320

167. Seeley RJ, Perlmutter A, Seeley VA. Inheritance and Longevity of Infectious Pancreatic Necrosis Virus in the Zebra Fish, Brachydanio Rerio (HamiltonBuchanan). Appl Environ Microbiol (1977) 34:50-5. doi: 10.1128/ AEM.34.1.50-55.1977

168. Lu MW, Chao YM, Guo TC, Santi N, Evensen O, Kasani SK, et al. The Interferon Response is Involved in Nervous Necrosis Virus Acute and Persistent Infection in Zebrafish Infection Model. Mol Immunol (2008) 45:1146-52. doi: 10.1016/j.molimm.2007.07.018

169. Binesh CP. Mortality Due to Viral Nervous Necrosis in Zebrafish Danio Rerio and Goldfish Carassius Auratus. Dis Aquat Organ (2013) 104:257-60. doi: $10.3354 /$ dao02605

170. Morick D, Faigenbaum O, Smirnov M, Fellig Y, Inbal A, Kotler M. Mortality Caused by Bath Exposure of Zebrafish (Danio Rerio) Larvae to Nervous Necrosis Virus is Limited to the Fourth Day Postfertilization. Appl Environ Microbiol (2015) 81:3280-7. doi: 10.1128/AEM.04175-14

171. Morick D, Saragovi A. Inhibition of Nervous Necrosis Virus by Ribavirin in a Zebrafish Larvae Model. Fish Shellfish Immunol (2017) 60:537-44. doi: 10.1016/j.fsi.2016.11.015

172. Van Dycke J, Ny A, Conceicao-Neto N, Maes J, Hosmillo M, Cuvry A, et al. A Robust Human Norovirus Replication Model in Zebrafish Larvae. PloS Pathog (2019) 15:e1008009. doi: 10.1371/journal.ppat.1008009

173. Altan E, Kubiski SV, Boros A, Reuter G, Sadeghi M, Deng X, et al. A Highly Divergent Picornavirus Infecting the Gut Epithelia of Zebrafish (Danio Rerio) in Research Institutions Worldwide. Zebrafish (2019) 16:291-9. doi: 10.1089/zeb.2018.1710

174. Levraud JP, Jouneau L, Briolat V, Laghi V, Boudinot P. Ifn-Stimulated Genes in Zebrafish and Humans Define an Ancient Arsenal of Antiviral Immunity. J Immunol (2019) 203:3361-73. doi: 10.4049/jimmunol.1900804

175. Passoni G, Langevin C, Palha N, Mounce BC, Briolat V, Affaticati P, et al. Imaging of Viral Neuroinvasion in the Zebrafish Reveals That Sindbis and Chikungunya Viruses Favour Different Entry Routes. Dis Model Mech (2017) 10:847-57. doi: 10.1242/dmm.029231

176. Boucontet L, Passoni G, Thiry V, Maggi L, Herbomel P, Levraud JP, et al. A Model of Superinfection of Virus-Infected Zebrafish Larvae: Increased Susceptibility to Bacteria Associated With Neutrophil Death. Front Immunol (2018) 9:1084. doi: 10.3389/fimmu.2018.01084

177. Ayala-Nunez NV, Follain G, Delalande F, Hirschler A, Partiot E, Hale GL, et al. Zika Virus Enhances Monocyte Adhesion and Transmigration Favoring Viral Dissemination to Neural Cells. Nat Commun (2019) 10:4430. doi: 10.1038/s41467-019-12408-x

178. Strange DP, Jiyarom B, Pourhabibi Zarandi N, Xie X, Baker C, SadriArdekani H, et al. Axl Promotes Zika Virus Entry and Modulates the Antiviral State of Human Sertoli Cells. mBio (2019) 10 10(4):e01372-19. doi: 10.1128/mBio.01372-19

179. Shen $\mathrm{CH}$, Steiner LA. Genome Structure and Thymic Expression of an Endogenous Retrovirus in Zebrafish. J Virol (2004) 78:899-911. doi: 10.1128/ JVI.78.2.899-911.2004

180. Frazer JK, Batchelor LA, Bradley DF, Brown KH, Dobrinski KP, Lee C, et al. Genomic Amplification of an Endogenous Retrovirus in Zebrafish T-cell Malignancies. Adv Hematol (2012) 2012:627920. doi: 10.1155/2012/627920

181. Sanders GE, Batts WN, Winton JR. Susceptibility of Zebrafish (Danio Rerio) to a Model Pathogen, Spring Viremia of Carp Virus. Comp Med (2003) 53:514-21.

182. Lopez-Munoz A, Roca FJ, Sepulcre MP, Meseguer J, Mulero V. Zebrafish Larvae are Unable to Mount a Protective Antiviral Response Against Waterborne Infection by Spring Viremia of Carp Virus. Dev Comp Immunol (2010) 34:546-52. doi: 10.1016/j.dci.2009.12.015

183. Encinas P, Garcia-Valtanen P, Chinchilla B, Gomez-Casado E, Estepa A, Coll J. Identification of Multipath Genes Differentially Expressed in
Pathway-Targeted Microarrays in Zebrafish Infected and Surviving Spring Viremia Carp Virus (SVCV) Suggest Preventive Drug Candidates. PloS One (2013) 8:e73553. doi: 10.1371/journal.pone.0073553

184. Kortum AN, Rodriguez-Nunez I, Yang J, Shim J, Runft D, O’Driscoll ML, et al. Differential Expression and Ligand Binding Indicate Alternative Functions for Zebrafish Polymeric Immunoglobulin Receptor (pIgR) and a Family of pIgR-like (PIGRL) Proteins. Immunogenetics (2014) 66:267-79. doi: 10.1007/s00251-014-0759-4

185. Novoa B, Romero A, Mulero V, Rodriguez I, Fernandez I, Figueras A. Zebrafish (Danio Rerio) as a Model for the Study of Vaccination Against Viral Haemorrhagic Septicemia Virus (VHSV). Vaccine (2006) 24:5806-16. doi: 10.1016/j.vaccine.2006.05.015

186. Chinchilla B, Gomez-Casado E, Encinas P, Falco A, Estepa A, Coll J. In Vitro Neutralization of Viral Hemorrhagic Septicemia Virus by Plasma From Immunized Zebrafish. Zebrafish (2013) 10:43-51. doi: 10.1089/zeb.2012.0805

187. Kavaliauskis A, Arnemo M, Kim SH, Ulanova L, Speth M, Novoa B, et al. Use of Poly(I:C) Stabilized With Chitosan as a Vaccine-Adjuvant Against Viral Hemorrhagic Septicemia Virus Infection in Zebrafish. Zebrafish (2015) 12:421-31. doi: 10.1089/zeb.2015.1126

188. Clarke BD, McColl KA, Ward AC, Doran TJ. shRNAs Targeting Either the Glycoprotein or Polymerase Genes Inhibit Viral Haemorrhagic Septicaemia Virus Replication in Zebrafish ZF4 Cells. Antiviral Res (2017) 141:124-32. doi: 10.1016/j.antiviral.2017.02.012

189. Liu X, Collodi P. Novel Form of Fibronectin From Zebrafish Mediates Infectious Hematopoietic Necrosis Virus Infection. J Virol (2002) 76:492-8. doi: 10.1128/JVI.76.2.492-498.2002

190. Ludwig M, Palha N, Torhy C, Briolat V, Colucci-Guyon E, Bremont M, et al. Whole-Body Analysis of a Viral Infection: Vascular Endothelium is a Primary Target of Infectious Hematopoietic Necrosis Virus in Zebrafish Larvae. PloS Pathog (2011) 7:e1001269. doi: 10.1371/journal.ppat.1001269

191. Aggad D, Stein C, Sieger D, Mazel M, Boudinot P, Herbomel P, et al. In Vivo Analysis of Ifn-gamma1 and Ifn-gamma2 Signaling in Zebrafish. J Immunol (2010) 185:6774-82. doi: 10.4049/jimmunol.1000549

192. Balkrishna A, Solleti SK, Verma S, Varshney A. Validation of a Novel Zebrafish Model of Dengue Virus (Denv-3) Pathology Using the Pentaherbal Medicine Denguenil Vati. Biomolecules (2020) 10 10(7):971. doi: 10.3390/ biom10070971

193. Shieh YS, Chang YS, Hong JR, Chen LJ, Jou LK, Hsu CC, et al. Increase of Hepatic Fat Accumulation by Liver Specific Expression of Hepatitis B Virus X Protein in Zebrafish. Biochim Biophys Acta (2010) 1801:721-30. doi: 10.1016/j.bbalip.2010.04.008

194. Liu W, Chen JR, Hsu CH, Li YH, Chen YM, Lin CY, et al. A Zebrafish Model of Intrahepatic Cholangiocarcinoma by Dual Expression of Hepatitis B Virus X and Hepatitis C Virus Core Protein in Liver. Hepatology (2012) 56:226876. doi: 10.1002/hep. 25914

195. Lu JW, Yang WY, Lin YM, Jin SL, Yuh CH. Hepatitis B Virus X Antigen and Aflatoxin B1 Synergistically Cause Hepatitis, Steatosis and Liver Hyperplasia in Transgenic Zebrafish. Acta Histochem (2013) 115:728-39. doi: 10.1016/ j.acthis.2013.02.012

196. Ding CB, Zhao Y, Zhang JP, Peng ZG, Song DQ, Jiang JD. A Zebrafish Model for Subgenomic Hepatitis C Virus Replication. Int J Mol Med (2015) 35:7917. doi: $10.3892 /$ ijmm. 2015.2063

197. Ding CB, Zhang JP, Zhao Y, Peng ZG, Song DQ, Jiang JD. Zebrafish as a Potential Model Organism for Drug Test Against Hepatitis C Virus. PloS One (2011) 6:e22921. doi: 10.1371/journal.pone.0022921

198. Gaiano N, Allende M, Amsterdam A, Kawakami K, Hopkins N. Highly Efficient Germ-Line Transmission of Proviral Insertions in Zebrafish. Proc Natl Acad Sci USA (1996) 93:7777-82. doi: 10.1073/pnas.93.15.7777

199. Lin S, Gaiano N, Culp P, Burns JC, Friedmann T, Yee JK, et al. Integration and Germ-Line Transmission of a Pseudotyped Retroviral Vector in Zebrafish. Science (1994) 265:666-9. doi: 10.1126/science.8036514

200. Burns JC, Friedmann T, Driever W, Burrascano M, Yee JK. Vesicular Stomatitis Virus G Glycoprotein Pseudotyped Retroviral Vectors: Concentration to Very High Titer and Efficient Gene Transfer Into Mammalian and Nonmammalian Cells. Proc Natl Acad Sci USA (1993) 90:8033-7. doi: 10.1073/pnas.90.17.8033

201. Chinchilla B, Gomez-Casado E. Identification of the Functional Regions of the Viral Haemorrhagic Septicaemia Virus (VHSV) NV Protein: Variants 
That Improve Function. Fish Shellfish Immunol (2017) 70:343-50. doi: 10.1016/j.fsi.2017.09.021

202. Kurath G, Kuhn J. (2016). ICTV taxonomic proposal 2016.018aM. A.v1.Novirhabdovirus_spren. rename 2 species in the genus Novirhabdovirus, family Rhabdoviridae.

203. Soliman MK, Aboeisa MM, Mohamed SG, Saleh WD. First Record of Isolation and Identification of Spring Viraemia of Carp Virus From Oreochromis Niloticus in Egypt. In: 8th International Symposium on Tilapia in Aquaculture. (2008) pp. 533-533.

204. Haghighi Khiabanian Asl A, Bandehpour M, Sharifnia Z, Kazemi B. The First Report of Spring Viraemia of Carp in Some Rainbow Trout Propagation and Breeding by Pathology and Molecular Techniques in Iran. Asian J Anim Vet Adv (2008) 3:263-8. doi: 10.3923/ajava.2008.263.268

205. He C, Bartholomew CR, Zhou W, Klionsky DJ. Assaying Autophagic Activity in Transgenic GFP-Lc3 and GFP-Gabarap Zebrafish Embryos. Autophagy (2009) 5:520-6. doi: 10.4161/auto.5.4.7768

206. Libran-Perez M, Pereiro P, Figueras A, Novoa B. Antiviral Activity of Palmitic Acid Via Autophagic Flux Inhibition in Zebrafish (Danio Rerio). Fish Shellfish Immunol (2019) 95:595-605. doi: 10.1016/j.fsi. 2019.10.055

207. Valenzuela-Munoz V, Pereiro P, Alvarez-Rodriguez M, Gallardo-Escarate C, Figueras A, Novoa B. Comparative Modulation of lncRNAs in Wild-Type and rag1-heterozygous Mutant Zebrafish Exposed to Immune Challenge With Spring Viraemia of Carp Virus (SVCV). Sci Rep (2019) 9:14174. doi: 10.1038/s41598-019-50766-0

208. Wang YQ, Lü L Fau - Weng SP, Weng Sp Fau - Huang JN, Huang Jn Fau Chan SM, Chan Sm Fau - He JG, He JG. (2007).

209. Xu X, Huang L, Weng S, Wang J, Lin T, Tang J, et al. Tetraodon Nigroviridis as a Nonlethal Model of Infectious Spleen and Kidney Necrosis Virus (ISKNV) Infection. Virology (2010) 406:167-75. doi: 10.1016/ j.virol.2010.07.003

210. Schneeman TA, Bruno ME, Schjerven H, Johansen FE, Chady L, Kaetzel CS. Regulation of the Polymeric Ig Receptor by Signaling Through TLRs 3 and 4: Linking Innate and Adaptive Immune Responses. J Immunol (2005) 175:376-84. doi: 10.4049/jimmunol.175.1.376

211. Weaver SC, Lecuit M. Chikungunya Virus and the Global Spread of a Mosquito-Borne Disease. New Engl J Med (2015) 372:1231-9. doi: 10.1056/ NEJMra1406035

212. Natrajan MS, Rojas A, Waggoner JJ. Beyond Fever and Pain: Diagnostic Methods for Chikungunya Virus. J Clin Microbiol (2019) 57(6):e003508-19. doi: 10.1128/JCM.00350-19

213. S. D YSNS and S. S. Herpes Simplex Type 1, Statpearls. Treasure Island (FL): StatPearls Publishing (2020). Sep 21, 2020.

214. Cadwallader AB, Yost HJ. Combinatorial Expression Patterns of Heparan Sulfate Sulfotransferases in Zebrafish: I. The 3-O-sulfotransferase Family. Dev Dyn (2006) 235:3423-31. doi: 10.1002/dvdy.20991

215. Hubbard S, Darmani NA, Thrush GR, Dey D, Burnham L, Thompson JM, et al. Zebrafish-Encoded 3-O-sulfotransferase-3 Isoform Mediates Herpes Simplex Virus Type 1 Entry and Spread. Zebrafish (2010) 7:181-7. doi: 10.1089/zeb.2009.0621

216. Baldwin J, Antoine TE, Shukla D, Tiwari V. Zebrafish Encoded 3-Osulfotransferase-2 Generated Heparan Sulfate Serves as a Receptor During HSV-1 Entry and Spread. Biochem Biophys Res Commun (2013) 432:672-6. doi: 10.1016/j.bbrc.2013.02.020

217. Yakoub AM, Rawal N, Maus E, Baldwin J, Shukla D, Tiwari V. Comprehensive Analysis of Herpes Simplex Virus 1 (HSV-1) Entry Mediated by Zebrafish 3-O-Sulfotransferase Isoforms: Implications for the Development of a Zebrafish Model of HSV-1 Infection. J Virol (2014) 88:12915-22. doi: 10.1128/JVI.02071-14

218. Ahn J, Barber GN. STING Signaling and Host Defense Against Microbial Infection. Exp Mol Med (2019) 51:1-10. doi: 10.1038/s12276-019-0333-0

219. Blight KJ, Norgard EA. Hcv Replicon Systems. In: SL Tan, editor. Hepatitis C Viruses: Genomes and Molecular Biology. Norfolk (UK): Horizon Bioscience (2006).

220. Li YC, Zhang MQ, Zhang JP. Opposite Effects of Two Human ATG10 Isoforms on Replication of a HCV Sub-Genomic Replicon are Mediated Via Regulating Autophagy Flux in Zebrafish. Front Cell Infect Microbiol (2018) 8:109. doi: 10.3389/fcimb.2018.00109
221. Brenner C, Galluzzi L, Kepp O, Kroemer G. Decoding Cell Death Signals in Liver Inflammation. J Hepatol (2013) 59:583-94. doi: 10.1016/ j.jhep.2013.03.033

222. Manicassamy B, Manicassamy S, Belicha-Villanueva A, Pisanelli G, Pulendran B, Garcia-Sastre A. Analysis of In Vivo Dynamics of Influenza Virus Infection in Mice Using a GFP Reporter Virus. Proc Natl Acad Sci USA (2010) 107:11531-6. doi: 10.1073/pnas.0914994107

223. Winata CL, Korzh S, Kondrychyn I, Zheng W, Korzh V, Gong Z. Development of Zebrafish Swimbladder: The Requirement of Hedgehog Signaling in Specification and Organization of the Three Tissue Layers. Dev Biol (2009) 331:222-36. doi: 10.1016/j.ydbio.2009.04.035

224. Hills SL, Fischer M, Petersen LR. Epidemiology of Zika Virus Infection. $J$ Infect Dis (2017) 216:S868-74. doi: 10.1093/infdis/jix434

225. Moore CA, Staples JE, Dobyns WB, Pessoa A, Ventura CV, Fonseca EB, et al. Characterizing the Pattern of Anomalies in Congenital Zika Syndrome for Pediatric Clinicians. JAMA Pediatr (2017) 171:288-95. doi: 10.1001/ jamapediatrics.2016.3982

226. Thangavel RR, Bouvier NM. Animal Models for Influenza Virus Pathogenesis, Transmission, and Immunology. J Immunol Methods (2014) 410:60-79. doi: 10.1016/j.jim.2014.03.023

227. Bouvier NM, Lowen AC. Animal Models for Influenza Virus Pathogenesis and Transmission. Viruses (2010) 2:1530-63. doi: 10.3390/v20801530

228. Narasaraju T, Yang E, Samy RP, Ng HH, Poh WP, Liew AA, et al. Excessive Neutrophils and Neutrophil Extracellular Traps Contribute to Acute Lung Injury of Influenza Pneumonitis. Am J Pathol (2011) 179:199-210. doi: 10.1016/j.ajpath.2011.03.013

229. Haslett C. Resolution of Acute Inflammation and the Role of Apoptosis in the Tissue Fate of Granulocytes. Clin Sci (Lond) (1992) 83:639-48. doi: $10.1042 / \operatorname{cs} 0830639$

230. Nguyen-Chi M, Phan QT, Gonzalez C, Dubremetz JF, Levraud JP, Lutfalla G. Transient Infection of the Zebrafish Notochord With E. Coli Induces Chronic Inflammation. Dis Model Mech (2014) 7:871-82. doi: 10.1242/dmm.014498

231. Pereiro P, Alvarez-Rodriguez M, Valenzuela-Munoz V, Gallardo-Escarate C, Figueras A, Novoa B. Rna-Seq Analysis Reveals That Spring Viraemia of Carp Virus Induces a Broad Spectrum of PIM Kinases in Zebrafish Kidney That Promote Viral Entry. Fish Shellfish Immunol (2020) 99:86-98. doi: 10.1016/j.fsi.2020.01.055

232. Farrell JA, Wang Y, Riesenfeld SJ, Shekhar K, Regev A, Schier AF. Single-Cell Reconstruction of Developmental Trajectories During Zebrafish Embryogenesis. Science (2018) 360(6392):eaar3131. doi: 10.1126/science.aar3131

233. Hou Y, Lee HJ, Chen Y, Ge J, Osman FOI, McAdow AR, et al. Cellular Diversity of the Regenerating Caudal Fin. $S c i A d v$ (2020) 6:eaba2084. doi: 10.1126/sciadv.aba2084

234. Yates AD, Achuthan P, Akanni W, Allen J, Allen J, Alvarez-Jarreta J, et al. Ensembl 2020. Nucleic Acids Res (2020) 48:D682-8. doi: 10.1093/nar/ gkz966

235. Chan J, Atianand M, Jiang Z, Carpenter S, Aiello D, Elling R, et al. Cutting Edge: A Natural Antisense Transcript, AS-ILlalpha, Controls Inducible Transcription of the Proinflammatory Cytokine IL-1alpha. J Immunol (2015) 195:1359-63. doi: 10.4049/jimmunol.1500264

236. Atianand MK, Hu W, Satpathy AT, Shen Y, Ricci EP, Alvarez-Dominguez JR, et al. A Long Noncoding RNA Lincrna-EPS Acts as a Transcriptional Brake to Restrain Inflammation. Cell (2016) 165:1672-85. doi: 10.1016/j.cell. 2016.05.075

237. Carpenter S, Aiello D, Atianand MK, Ricci EP, Gandhi P, Hall LL, et al. A Long Noncoding RNA Mediates Both Activation and Repression of Immune Response Genes. Science (2013) 341:789-92. doi: 10.1126/ science.1240925

238. Zhou W, Pal AS, Hsu AY, Gurol T, Zhu X, Wirbisky-Hershberger SE, et al. Microrna-223 Suppresses the Canonical NF-Kappab Pathway in Basal Keratinocytes to Dampen Neutrophilic Inflammation. Cell Rep (2018) 22:1810-23. doi: 10.1016/j.celrep.2018.01.058

239. Bazzini AA, Lee MT, Giraldez AJ. Ribosome Profiling Shows That miR-430 Reduces Translation Before Causing mRNA Decay in Zebrafish. Science (2012) 336:233-7. doi: 10.1126/science.1215704

240. Yin VP, Lepilina A, Smith A, Poss KD. Regulation of Zebrafish Heart Regeneration by Mir-133. Dev Biol (2012) 365:319-27. doi: 10.1016/ j.ydbio.2012.02.018 
241. Yin VP, Thomson JM, Thummel R, Hyde DR, Hammond SM, Poss KD. FgfDependent Depletion of microRNA-133 Promotes Appendage Regeneration in Zebrafish. Genes Dev (2008) 22:728-33. doi: 10.1101/gad.1641808

242. Tarver JE, Sperling EA, Nailor A, Heimberg AM, Robinson JM, King BL, et al. miRNAs: Small Genes With Big Potential in Metazoan Phylogenetics. Mol Biol Evol (2013) 30:2369-82. doi: 10.1093/molbev/mst133

243. Fromm B, Billipp T, Peck LE, Johansen M, Tarver JE, King BL, et al. A Uniform System for the Annotation of Vertebrate Microrna Genes and the Evolution of the Human Micrornaome. Annu Rev Genet (2015) 49:213-42. doi: 10.1146/annurev-genet-120213-092023
Conflict of Interest: The authors declare that the research was conducted in the absence of any commercial or financial relationships that could be construed as a potential conflict of interest.

Copyright $\odot 2021$ Sullivan, Soos, Millard, Kim and King. This is an open-access article distributed under the terms of the Creative Commons Attribution License (CC BY). The use, distribution or reproduction in other forums is permitted, provided the original author(s) and the copyright owner(s) are credited and that the original publication in this journal is cited, in accordance with accepted academic practice. No use, distribution or reproduction is permitted which does not comply with these terms. 